\title{
Impact of satellite viewing-swath width on global and regional aerosol optical thickness statistics and trends
}

\author{
P. R. Colarco ${ }^{1}$, R. A. Kahn ${ }^{2}$, L. A. Remer ${ }^{3}$, and R. C. Levy ${ }^{2}$ \\ ${ }^{1}$ Atmospheric Chemistry and Dynamics Laboratory (Code 614), NASA Goddard Space Flight Center, Greenbelt, \\ MD 20771, USA \\ ${ }^{2}$ Climate and Radiation Laboratory (Code 613), NASA Goddard Space Flight Center, Greenbelt, MD 20771, USA \\ ${ }^{3}$ Joint Center for Earth Systems Technology, University of Maryland-Baltimore County, 5523 Research Park Dr., Suite 320, \\ Baltimore, MD 21250, USA \\ Correspondence to: P. R. Colarco (peter.r.colarco@nasa.gov)
}

Received: 25 September 2013 - Published in Atmos. Meas. Tech. Discuss.: 27 November 2013

Revised: 6 May 2014 - Accepted: 17 June 2014 - Published: 31 July 2014

\begin{abstract}
We use the Moderate Resolution Imaging Spectroradiometer (MODIS) satellite aerosol optical thickness (AOT) product to assess the impact of reduced swath width on global and regional AOT statistics and trends. Alongtrack and across-track sampling strategies are employed, in which the full MODIS data set is sub-sampled with various narrow-swath $(\sim 400-800 \mathrm{~km})$ and single pixel width $(\sim 10 \mathrm{~km})$ configurations. Although view-angle artifacts in the MODIS AOT retrieval confound direct comparisons between averages derived from different sub-samples, careful analysis shows that with many portions of the Earth essentially unobserved, spatial sampling introduces uncertainty in the derived seasonal-regional mean AOT. These AOT spatial sampling artifacts comprise up to $60 \%$ of the full-swath AOT value under moderate aerosol loading, and can be as large as 0.1 in some regions under high aerosol loading. Compared to full-swath observations, narrower swath and single pixel width sampling exhibits a reduced ability to detect AOT trends with statistical significance. On the other hand, estimates of the global, annual mean AOT do not vary significantly from the full-swath values as spatial sampling is reduced. Aggregation of the MODIS data at coarse grid scales $\left(10^{\circ}\right)$ shows consistency in the aerosol trends across sampling strategies, with increased statistical confidence, but quantitative errors in the derived trends are found even for the full-swath data when compared to high spatial resolution $\left(0.5^{\circ}\right)$ aggregations. Using results of a model-derived aerosol reanalysis, we find consistency in our conclusions about a seasonal-regional spatial sampling artifact in AOT.
\end{abstract}

Furthermore, the model shows that reduced spatial sampling can amount to uncertainty in computed shortwave top-ofatmosphere aerosol radiative forcing of $2-3 \mathrm{~W} \mathrm{~m}^{-2}$. These artifacts are lower bounds, as possibly other unconsidered sampling strategies would perform less well. These results suggest that future aerosol satellite missions having significantly less than full-swath viewing are unlikely to sample the true AOT distribution well enough to obtain the statistics needed to reduce uncertainty in aerosol direct forcing of climate.

\section{Introduction}

The direct and indirect effects of aerosols remain the largest uncertainties in estimates of the anthropogenic forcing of Earth's climate system (Solomon et al., 2007). Although a conceptually simpler problem than the indirect effects of aerosols on clouds, the direct effect due to scattering and absorption of radiation itself remains poorly constrained owing to uncertainty in aerosol loading, temporal and spatial distribution, and physical properties (Loeb and Su, 2010; Kahn, 2012). The uncertainty in the anthropogenic direct aerosol radiative forcing (DARF) component drives much of the uncertainty in overall anthropogenic climate forcing for current climate models (Kiehl, 2007).

Attempts to quantify aerosol properties from satellite observations have been made since the 1970s, albeit generally with instruments not optimized for observing aerosols. 
Since the late 1990 s, a suite of satellite instruments designed to measure aerosol properties has helped refine estimates of aerosol loading, and has contributed some progress on retrieving other properties (e.g., absorption, particle size, shape, and vertical distribution) (see CCSP, 2009, and references therein). Despite these advances, large uncertainties remain, and further reduction of the direct aerosol radiative forcing uncertainty requires improved satellite coverage, as well as integration with in situ observations of aerosol type and transport models for synthesis (Diner et al., 2004; Anderson et al., 2005; Kahn, 2012).

Given the current state of affairs, design requirements for the next-generation, space-based aerosol observing instruments is a topic of particular importance. For example, in 2004, the US National Aeronautics and Space Administration (NASA), National Oceanic and Atmospheric Administration (NOAA), and US Geological Survey (USGS) requested the US National Research Council (NRC) to "conduct a decadal survey to generate consensus recommendations from the Earth and environmental science and applications communities" regarding needed space-based and ancillary observations to meet future research and operational priorities for these agencies (NRC, 2007; hereafter referred to as the "decadal survey"). Among the decadal survey recommended mission concepts was the AerosolCloud-Ecosystems (ACE) mission, which would have as its primary goal the reduction of uncertainty about climate forcing due to aerosols and oceanic $\mathrm{CO}_{2}$ uptake. A multi-sensor, sun-synchronous polar orbiting measurement platform was proposed for ACE in the decadal survey.

In designing a satellite mission, such as the ACE mission, there are various trade spaces to consider, an important one of which is spatial coverage. Given technological and budgetary constraints, trade-offs between the benefit of spatial coverage and other desired instrument characteristics must be considered, such as the number of spectral and polarized channels, relative precision and accuracy, angular and temporal coverage, and pixel size. The challenges of navigating these trade spaces for the aerosol problem were recognized in a series of papers describing the Progressive Aerosol Retrieval and Assimilation Global Observing Network (PARAGON, see especially Diner et al., 2004; Seinfeld et al., 2004). Anderson et al. (2003) addressed the specific question of aerosol spatial variability with ground-based and airborne measurements, as well as observations from a lidar system flown on the NASA Space Shuttle (STS-64), finding important mesoscale (40-400 km) structure in aerosol features to be common in their data sets. For ACE, the decadal survey explicitly called for across-track coverage to resolve this mesoscale structure, requirements for which were refined somewhat in NASA's response to the decadal survey ACE concept (Starr et al., 2010), but those requirements had not been determined from any systematic study of aerosol observations, and the aforementioned conclusions from Anderson et al. (2003) were based on spatially and temporally limited data sets.
Taking advantage of the broader spatial and temporal coverage afforded by the current space-based, wide-swath Moderate Resolution Imaging Spectroradiometer (MODIS, see Sect. 2.2), Geogdzhayev et al. (2013) investigated the implications of along-track only sampling on statistics of global monthly mean aerosol optical thickness (AOT). AOT is relevant to the question of DARF, as it is a proxy for aerosol column loading, and because to first order it determines DARF. Hansen et al. (1995) suggest that a change in the global mean AOT of 0.01 corresponds to a climatically important change in the global mean radiative forcing of $0.25 \mathrm{~W} \mathrm{~m}^{-2}$. This can be compared with the $0.5 \pm 0.4 \mathrm{~W} \mathrm{~m}^{-2}$ Intergovernmental Panel on Climate Change (IPCC)-stated uncertainty in the magnitude of the anthropogenic DARF component (Solomon et al., 2007). Other analyses suggest that the actual uncertainty is far larger than the IPCC estimate (McComiskey et al., 2008; Loeb and Su, 2010). Arguing from their analysis of MODIS AOT retrievals, Geogdzhayev et al. (2013) concluded that narrow along-track-only sampling, only one pixel wide, is sufficient to constrain the global, monthly mean average AOT, and is therefore adequate for climate applications. They did not, however, address implications of reduced spatial sampling on regional AOT, or the uncertainty in decadalscale AOT trends.

In this paper we re-examine the question of the impact of spatial sampling for a sun-synchronous polar orbiting satellite on the statistics of AOT. We approach this question using two complementary data sets. The first data set explored is the AOT retrieval product from the MODIS instrument aboard the NASA Aqua spacecraft, as in Geogdzhayev et al. (2013). Several different along-track and across-track sampling strategies are applied to the MODIS observations in order to sub-sample the data set. The second data set is derived from a newly available aerosol reanalysis performed in the NASA Goddard Earth Observing System (GEOS-5) model. GEOS-5 is an Earth system model that includes an online aerosol module, and is run in our case using assimilated meteorology and invoking assimilation of AOT from satellite observations. In Sect. 2 we describe and present results of our sampling study as applied to the MODIS data set. In Sect. 3 we investigate the question of spatial sampling in the context of the GEOS-5 model results. Section 4 presents a discussion of our results and our conclusions.

\section{Spatial sampling of the MODIS data set}

\subsection{A conceptual illustration of the spatial sampling problem}

At any given time, nature presents us with a particular threedimensional spatial distribution of clouds and aerosols, as well as the attendant variability in particle microphysical characteristics, surface reflectivity, and solar illumination. The passive satellite instrument retrieval problem amounts 
to inverting a meaningful geophysical quantity (e.g., AOT) from this complexity, given a limited set of measured parameters (e.g., backscattered spectral reflectance). Our hypothesis is that the ability to tease out the climatically significant portion of this signal for synoptically important events depends in part on the spatial and temporal coverage of the observing system. In this paper we focus on spatial coverage as determined by the sensor's viewing-swath width.

We illustrate the spatial coverage aspects of the problem conceptually in Fig. 1. The global aerosol field is represented with a familiar painting (Fig. 1a). In a perfect observing system we would see the true aerosol field at all times and locations, but lacking that we are constrained by the realities of our instrument's spatial and temporal coverage, as well as by the challenges inherent in the retrieval problem itself. We show this using a single day's coverage of the aerosol field retrieved by the MODIS instrument aboard the Aqua spacecraft. Superimposed on the painting are the orbital gaps, clouds, and bright surfaces where the MODIS "dark target" aerosol retrieval is not applied. Note the large white area in the shape of the Saharan and Arabian deserts over the figure's left eye (Fig. 1b). For purposes of our illustration, we are making the assumption that our "true" scene is time invariant, as it would take MODIS $24 \mathrm{~h}$ to achieve the coverage shown in Fig. 1b. If we narrow our view further, assuming something like the spatial coverage of the NASA Multi-angle Imaging Spectroradiometer (MISR) instrument, we obtain the scene in Fig. 1c, and further reduction of the coverage to a single pixel wide "curtain" along the MODIS track yields Fig. 1d. This sampling construction is formally developed in Sect. 2.3. Figure 1 illustrates that very different pictures of the "true" scene emerge depending on the spatial coverage of the observing system. In what follows, we quantify the impact of spatial coverage characterizing the time varying global and regional field of AOT.

\subsection{The MODIS data set}

We use aerosol observations from the space-based MODIS instrument for this part of our study. MODIS provides nearglobal, daily AOT retrievals over land and ocean surfaces. There are two MODIS instruments, both in sun-synchronous polar orbits. MODIS on the Terra satellite has been operational since early 2000 and has a daytime equator crossing time of about 10:30 a.m. local time (LT) at the center of its swath. MODIS on the Aqua satellite has been operational since mid-2002 and has a daytime equator crossing time of about 01:30 p.m. LT. At the nominal orbit altitude of $704 \mathrm{~km}$, the MODIS instruments observe a swath about $2300 \mathrm{~km}$ wide along their ground tracks. The MODIS orbit is such that the ground coverage is repeated exactly every 16 days. AOT is retrieved in the daytime portion of the MODIS orbit under cloud-free and glint-free conditions using separate aerosol retrieval algorithms for ocean (Tanré et al., 1996, 1997) and land (Kaufman et al., 1997; Levy et al., 2007a, b).
In our analysis, we use the land and ocean AOT retrievals from the MODIS Aqua instrument, valid at $550 \mathrm{~nm}$, from the Collection 5 MODIS algorithm products (Remer et al., 2005, 2008; Levy et al., 2010). The retrievals are made at a nominal $10 \mathrm{~km} \times 10 \mathrm{~km}$ spatial resolution at nadir. A quality assurance (QA) flag is reported for each retrieval, indicating its estimated level of confidence as a valid result, from tests performed during the retrieval process. QA flags range from 0 (lowest confidence) to 3 (highest confidence). In order to retain the highest quality MODIS data, in what follows we use only the highest confidence $(\mathrm{QA}=3)$ retrievals over land, and require QA $>0$ over ocean (Remer et al., 2008; Levy et al., 2010; Bréon et al., 2011). The uncertainty in the MODIS AOT $(\tau)$ product is characterized such that one standard deviation $(66 \%)$ of the retrievals fall within $\Delta \tau= \pm 0.03 \pm 0.05 \tau$ over the ocean and $\Delta \tau= \pm 0.05 \pm 0.15 \tau$ over land relative to the AOT from coincident ground-based AERONET sun photometer network observations (Remer et al., 2005). The AOT data set thusly obtained is representative of the clearsky (cloud-free) aerosol distribution, and it should be understood that a portion of our subsequent spatial sub-sampling (see next section) is entwined with the spatial sampling of clouds.

\subsection{Methodology for along-track sub-sampling of AOT from the MODIS full swath}

Our spatial sampling strategies are illustrated in Fig. 2, which shows an example over-ocean scene comprising a single MODIS Aqua swath. Along-track spatial sub-sampling (along the MODIS orbital track) is illustrated in Fig. 2a. We consider the AOT retrieved across the MODIS full swath (FS), as well as several sub-sampled swaths in which we retain only the relevant portions of the full swath. Four narrow swaths are chosen to approximate the $\sim 380 \mathrm{~km}$ wide swath of the Multi-angle Imaging Spectroradiometer (MISR, on the Terra spacecraft, Diner et al., 1998), labeled: N1 east side of full swath, N2 - adjacent to N1, N3 - adjacent to N2 and in center of swath, and N4 - west side of swath. We also consider a "mid-width" swath (MW) with coverage between the narrow and full swath composed of the union of $\mathrm{N} 1$ and N2. To approximate the "curtain"-like sampling of an instrument such as the Cloud Aerosol Lidar with Orthogonal Polarization (CALIOP, aboard the CALIPSO spacecraft, Winker et al., 2010), we consider the samplings C1, C2, C3, and $\mathrm{C} 4$, which are extracted at the center of the N1, N2, $\mathrm{N} 3$, and N4 swaths, respectively. As will be explained below, the MODIS glint artifact particularly impacts the N3 and $\mathrm{C} 3$ samplings. We emphasize that in what follows, we are using only MODIS AOT retrievals, sub-sampling the full data set along the indicated narrow and curtain swaths. The sampling strategies are summarized in Table 1. Figure 2 also shows across-track sampling and sampling of global model data that will be described and used in Sects. 2.5 and 3.2, respectively. 

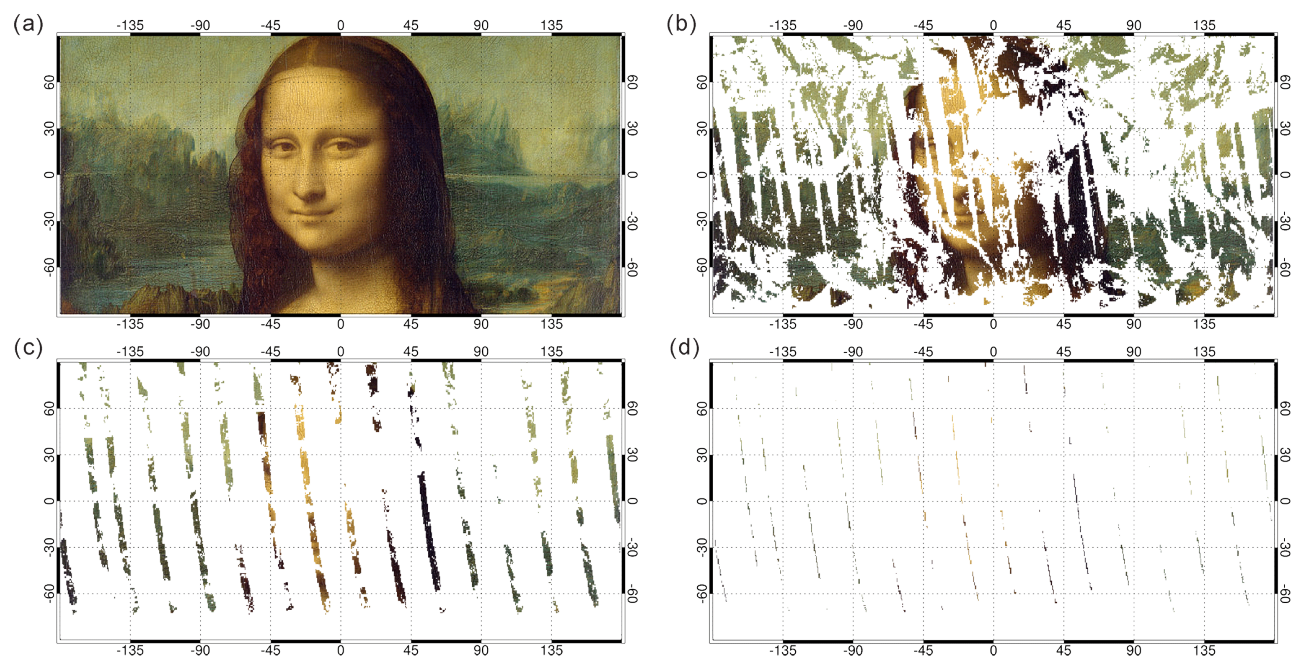

Figure 1. Conceptual illustration of the spatial sampling problem. Nature presents us with a "true" scene (a). The truth is sampled according to "full-swath" sampling of the MODIS instrument on the Aqua spacecraft (b), a "narrow" sampling (c), and a single pixel wide "curtain" sampling (d). For purposes of this illustration we are recovering only parts of the "true" image that had valid aerosol retrievals on 5 June 2010 from the MODIS over-ocean and "dark target" land retrievals.

The individual retrievals after sampling are aggregated onto regular latitude-longitude spatial grids typical of the grids used in global aerosol transport models. We will in this paper consider two grid resolutions: $0.5^{\circ} \times 0.625^{\circ}$ and $10^{\circ} \times 10^{\circ}$. For each, the grid-averaged AOT is

$\tau_{\text {grid }}=\frac{\sum_{i=1}^{n} \tau_{i} \cdot q_{i}}{\sum_{i=1}^{n} q_{i}}$,

where $\tau_{i}$ are the 1 through $n$ individual AOT retrievals falling into the grid box and $q_{i}$ is the QA value assigned to each retrieval. Our aggregation is thus QA weighted. Over land we have only retained $\mathrm{QA}=3$ retrievals, based on the MODIS Aerosol Product Data Quality Statement. The aggregation is performed daily. The temporally averaged (e.g., monthly, seasonal, annual) AOT at a grid box is

$\langle\tau\rangle=\frac{\sum_{j=1}^{m} \tau_{\text {grid }, j} \cdot n_{j}}{\sum_{j=1}^{m} n_{j}}$,

where $m$ is the number of days to average, $\tau_{\text {grid, } j}$ is the grid average value at day $j$ from Eq. (1), and $n_{j}$ is the number of retrievals used to make $\tau_{\text {grid, } j}$. This aggregation and weighting strategy is the same as in Remer et al. (2008) and Colarco et al. (2010).

\subsection{Along-track sub-sampling results}

\subsubsection{The sub-sampled AOT}

The sub-sampled MODIS Aqua AOT data are analyzed for the years 2003-2012. Figure 3a shows, for example, the year 2010 annually averaged AOT from the full-swath MODIS Aqua retrievals over both land and ocean using the aggregation strategy given by Eqs. (1) and (2) and the $0.5^{\circ} \times 0.625^{\circ}$ aggregation grid. The spatial patterns of the main aerosol features are evident: the Saharan dust and Asian pollution and dust outflow plumes, the biomass burning activity over southern Africa and South America, the pollution plume over China, the band of high AOT in the southern ocean, and a region of high AOT over western Russia where a significant biomass burning anomaly occurred in 2010 (Witte et al., 2011).

For comparison, the corresponding 2010 annual mean AOT of one of our narrow (N1) and two of our curtain (C1 and C3) samplings are shown in Fig. 3b, c, and d, respectively. As seen in Fig. 2, N1 and $\mathrm{C} 1$ are on the eastern edge of the MODIS swath. C3 is down the center of the swath and is particularly impacted by the sunglint artifact, and so has relatively poor retrieval sampling over the tropical ocean. Many of the features apparent in the full-swath annual mean in Fig. 3a are still apparent in the sub-samples: the biomass burning plumes over South America and southern Africa, the Asian outflow across the northern Pacific, Saharan dust transport across the North Atlantic, and dust and anthropogenic pollution over India and China. On the other hand, the shapes and apparent magnitudes of these features are clearly different, and certain features are notably absent, particularly the Saharan dust plume in the C3 sampling (mostly in the glint 

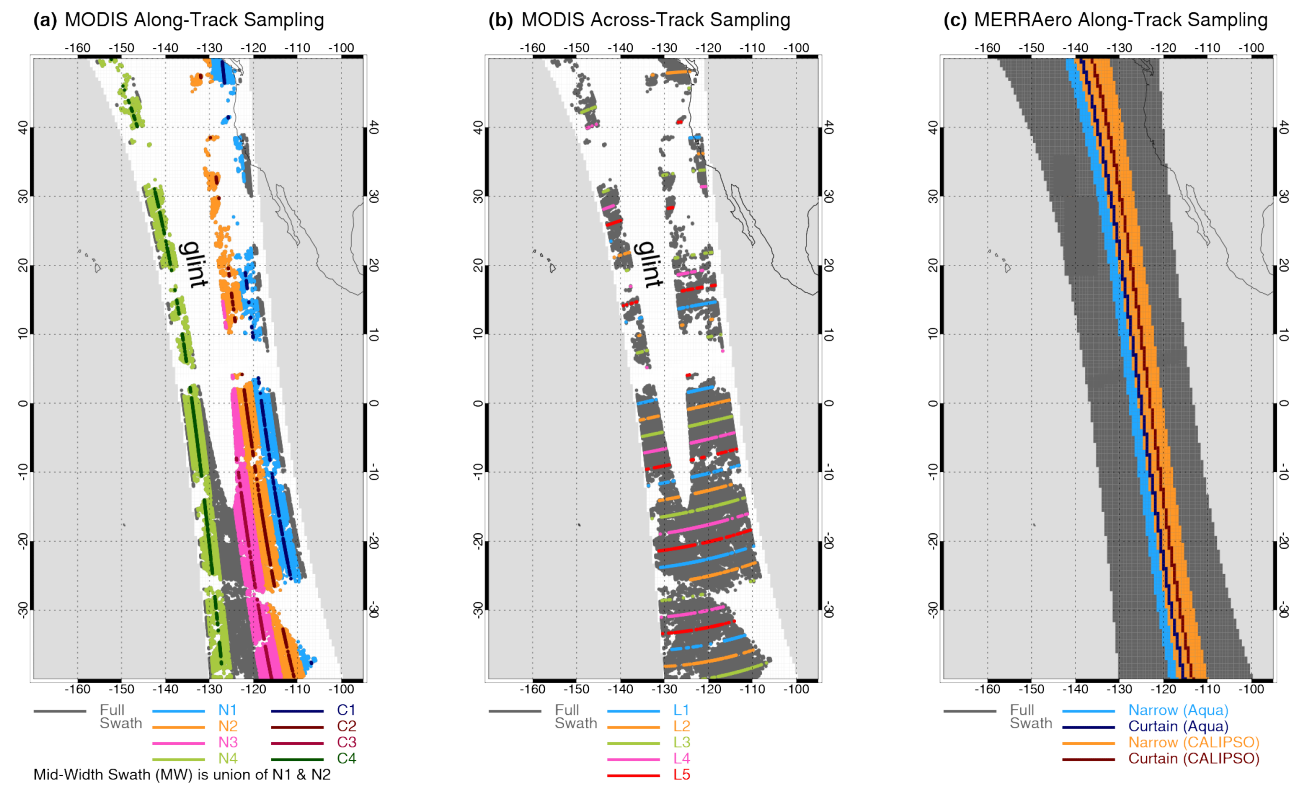

Figure 2. Spatial sampling strategies used in this paper illustrated for an example portion of an over-ocean orbit track of the Aqua spacecraft on 5 June 2010. (a) Along-track sampling illustration. The colored dots indicate the locations of the MODIS AOT retrievals, with the grey dots indicating the full MODIS swath (MO). Overlaid on the grey dots are different colors for our various along-track sampling strategies $(\mathrm{N} 1=$ light blue, $\mathrm{N} 2=$ orange, $\mathrm{N} 3=$ magenta, $\mathrm{N} 4=$ light green, $\mathrm{C} 1=$ dark blue, $\mathrm{C} 2=$ dark red, $\mathrm{C} 3=$ deep purple, $\mathrm{C} 4=$ dark green, and MW = combined N1 and N2 swath). The light-grey shaded areas on the left and right side of the figure are outside the swath, while the central white region (labeled "glint") is where no aerosol retrievals are made due to glint. Remaining patchy white areas are where aerosol retrievals were not made due to clouds. (b) As in (a) except illustrating across-track sampling following Geogdzhayev et al. (2013). (c) Along-track sampling strategy for MERRAero model output. Dark grey shading is the MODIS Aqua full swath. Light and dark blue are respectively the narrow and curtain width sampling along the Aqua ground track. Orange and dark red are respectively the narrow and curtain width sampling along the CALIPSO ground track. Note the absence of cloud or glint features in the model sampling.

Table 1. Summary of spatial sampling strategies illustrated in Fig. 2 and summary of temporal averaging approaches.

\begin{tabular}{ll}
\hline Sample name & Sample width \\
\hline Full swath (FS) & $\sim 2300 \mathrm{~km}$ \\
Mid-width (MW) & $\sim 800 \mathrm{~km}$ \\
Narrow (4 variants: N1, N2, N3, N4) & $\sim 380 \mathrm{~km}$ \\
Curtain (4 variants: C1, C2, C3, C4) & $\sim 10 \mathrm{~km}$ (width of MODIS pixel) \\
\hline Averaging strategy & Procedure \\
\hline Sample-then-average & Per orbit, sample the MODIS full swath at the indicated sub-swath \\
& Aggregate sub-sample to spatial grid \\
& Average aggregates to the desired time period \\
& (e.g., monthly, seasonal, annual) \\
Average-then-mask & Per orbit, aggregate the MODIS full swath to spatial grid \\
& Average to the desired time period \\
& Use "sample-then-average" result for relevant \\
& sub-sample/temporal average to retain or \\
& exclude grid boxes visited in sub-sample \\
\hline
\end{tabular}

region) and the high AOT features over the southwest United States in the $\mathrm{C} 1$ and N1 samplings. Other features, such as the 2010 Russian fires (Witte et al., 2011), still exhibit similar magnitude of AOT across sampling strategies, but their spatial coherence is quite different. Grey shading indicates places where no retrievals are available at all during the year.

We emphasize that in Fig. 3 the approach is "samplethen-average," and so is done on a "per-orbit" basis (see 



Figure 3. MODIS Aqua year 2010 annual mean AOT using the sampling and aggregation strategy in Eqs. (1) and (2) shown for various along-track spatial samplings: (a) full swath, (b) N1, (c) C1, and (d) C3. The grey shading indicates locations where no MODIS AOT retrievals were made during the year.

Table 1). Only the MODIS retrievals that could have been sampled are pulled from the full-swath data set, then aggregated, and then finally averaged. This "sample-then-average" approach is how time averages are typically calculated from polar orbiting satellite data sets. We make this point to distinguish from a different sampling approach discussed later (Sect. 2.4.2).

Figure 4 shows the years 2003-2012 time series of global, annual mean AOT over both land and ocean for each of our sampling strategies generated with a similar procedure to what is shown in Fig. 3 (grey lines). Also shown in Fig. 4 are the global annual mean AOT resulting from other sampling approaches, to be discussed in Sects. 2.4.2, 2.5, and 3.1.

The full-swath annual mean AOT varies between about 0.13 and 0.14 over the ocean and between about 0.16 and 0.18 over the land, similar to the multi-year analysis presented in Remer et al. (2008). We compare the global, annual mean AOT of our various sampling strategies to the full-swath AOT. Over ocean, except for the N4 and C4 samplings, the global, annual mean AOT is within 0.01 of the full-swath value. Over land, most of the sampling strategies differ from the full swath by more than 0.01 at some point in the time series, with $\mathrm{N} 1$ and $\mathrm{C} 1$ notably underestimating the global, annual mean AOT relative to the full swath. The excursions of the individual sampling strategies global, annual mean AOT from the full-swath mean can be as much as $15 \%$ of the full-swath magnitude. This is important, because if the narrow-swath or curtain-like sampling cannot reproduce the basic statistics of the full-swath AOT even at the global and annual scales, the question of whether we can rely on this measurement strategy for narrowing the uncertainties in key aerosol properties and their impacts on climate must be assessed quantitatively.

There is, however, a significant caveat to our along-track, "sample-then-average" results as presented in Fig. 4. Although the differences between any given sub-sample and the full-swath AOT certainly contain a component related to the spatial sampling, errors and uncertainties in the MODIS retrievals themselves also contribute to the differences shown. In particular, the MODIS AOT retrieval has a sensor viewangle dependency (Levy et al., 2010). That is, if the aerosol loading is homogeneous across the MODIS swath, different AOT values will under some circumstances nevertheless be retrieved in different positions across the swath, owing to this angular artifact. However, the characteristic of that artifact as a function of view angle, sun angle, position on Earth, 

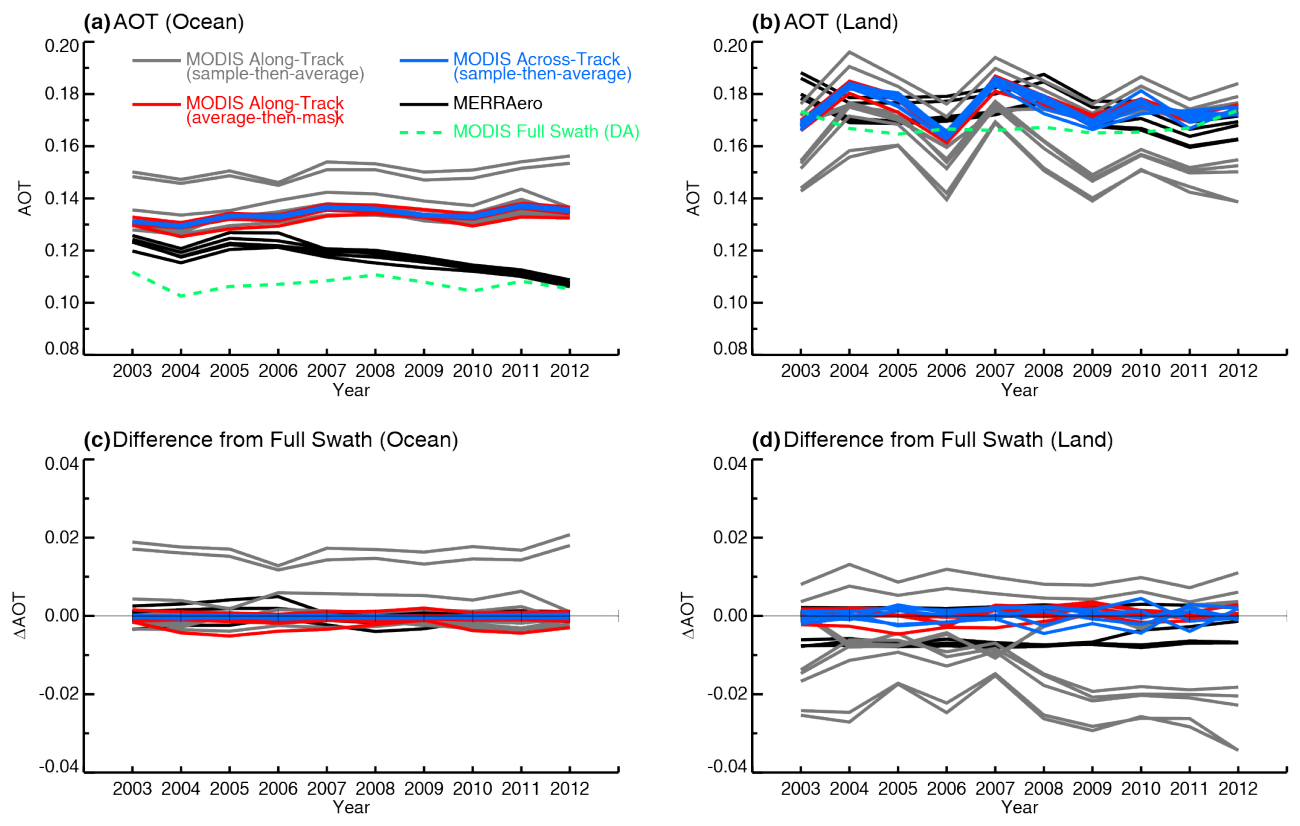

Figure 4. A time series for the years 2003-2012 of the global, annual mean MODIS Aqua AOT over ocean (a) and land (b). Grey shaded lines are the MODIS along-track sample-then-average approach. Red lines are the MODIS along-track average-then-mask approach. Blue lines are the across-track sampling following Geogzhayev et al. (2013). Black lines are the MERRAero along-track sampling. Different lines within each color group are the various sampling candidates explored. The bottom panels (c, d) in each is the difference of the individual sub-sampled averages from the respective full-swath average. Individual MERRAero sub-samples are differenced relative to the MERRAero full-swath (Aqua) sampling. Others are relative to the MODIS Aqua full-swath sampling. On top panels only, green dashed line is the data assimilation (DA) grade MODIS AOT assimilated in MERRAero (see text).

surface reflectance, etc., is not well understood. In an earlier study on the sampling question posed here (Colarco et al., 2012), we attempted to correct for this dependency by examining a data set of MODIS-AERONET collocations sorted by view geometry, similar to what is shown in Levy et al. (2010) (see, for example, their Fig. 10). This proved challenging. The collocation data set was relatively small and was only available where AERONET sites are located. The latter point made it difficult to evaluate the view-angle dependency of the MODIS AOT retrievals, especially over ocean. The data set would have been smaller still for determining these viewangle dependencies on a seasonal or regional basis. For these reasons, we could not separate view angle from spatial sampling differences when the full-swath and sub-sample AOT data sets were compared using the sample-then-average approach so far employed, so from this point forward we take a different approach to evaluate the impact of swath width on global AOT statistics.

\subsubsection{Application of an observability criterion to the MODIS data set}

Although we cannot correct the MODIS observations for the view-angle dependency with confidence, we can investigate the question of observability: what are the characteristics of the observations that are not made in a given sub-sample, and how does this impact the derived AOT statistics?

Figure 5 complements Fig. 3. It shows the 2010 fullswath annual mean AOT from Fig. 3a, but only in grid boxes where the indicated sub-sampling strategy had no valid annual mean AOT (i.e., in grid boxes where the sub-sample either never visited because of coverage limitations, or else never encountered a good AOT retrieval because of algorithmic issues when it did overfly the grid box). We show this for $\mathrm{N} 1, \mathrm{~N} 3, \mathrm{C} 1$, and C3 sub-samples. This is revealing. The N1 and N3 figures show that, like the full-swath sampling, the narrow-swath sampling permits retrieval of AOT over most points on Earth at least once during the year. However, in some places where the full-swath sampling would have made relatively few observations, the narrow-swath sampling provides no observations at all. (See Fig. 6, which shows the number of aerosol retrievals in each grid cell considered for several of the sampling strategies discussed in this paper.) These regions are generally where seasonal changes in surface brightness due to vegetation (e.g., the US southwest, the Sahel) or seasonal snow cover (the Tibetan plateau) make retrieval difficult and thus less frequent. On the other hand, Fig. 5 illustrates something qualitatively different when only curtain-like sampling is obtained: it is clear that much of the Earth is never visited at all under this sampling. 

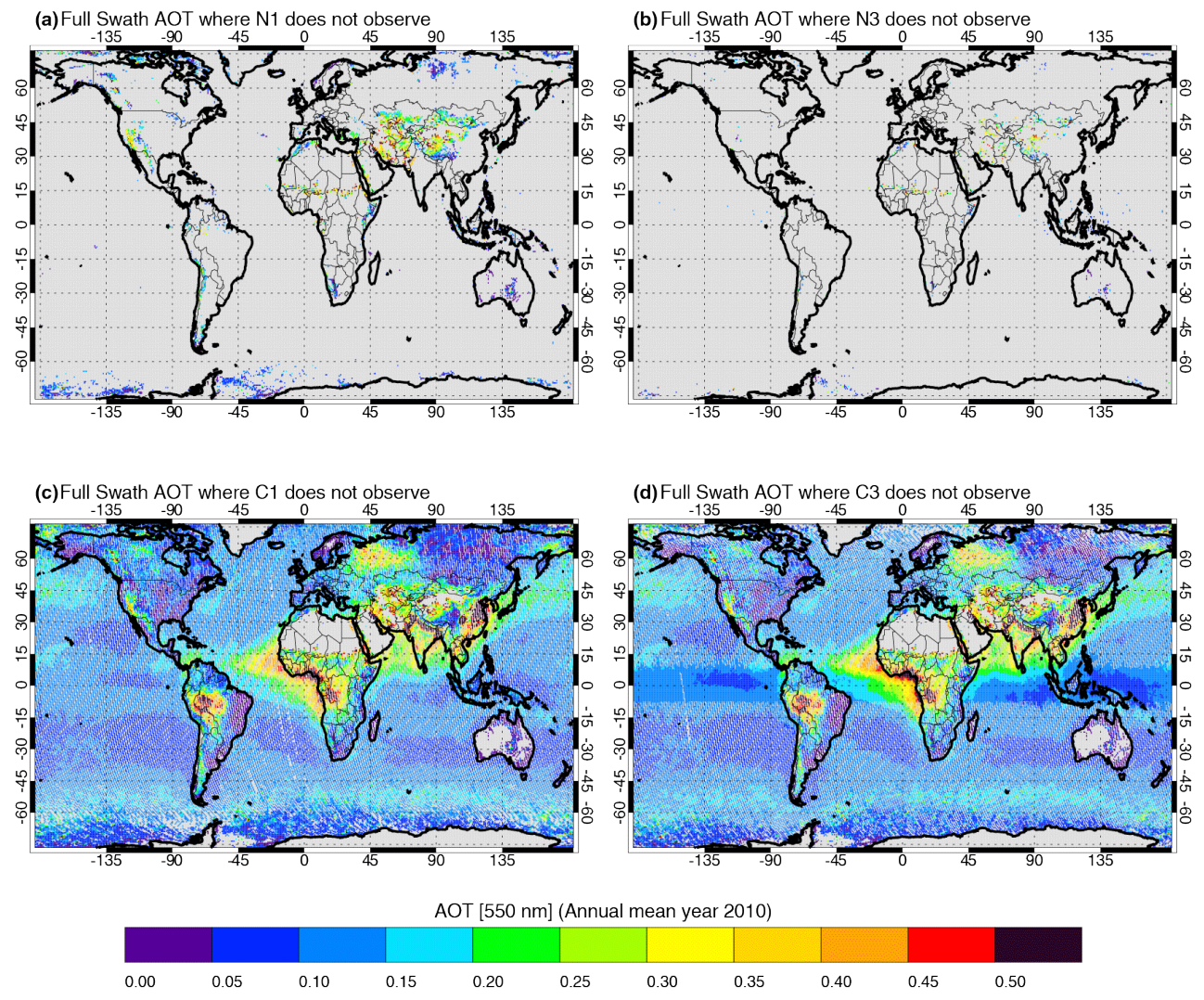

Figure 5. MODIS Aqua full swath year 2010 annual mean AOT shown only at points never sampled by the indicated sub-sample swath: (a) N1, (b) N3, (c) C1, and (d) C3.

In our analysis of observability, to reduce the issue of the view-angle artifact discussed above we create what we call our "average-then-mask" strategy (Table 1). First, we construct monthly, seasonal, or annual mean maps of the AOT from the full-swath data, effectively sampling the location at all viewing geometries obtained by MODIS. Second, we create masks that exclude the grid boxes never observed by each particular sampling strategy over the relevant averaging period. Finally, we apply the masks to the aggregated maps of the full-swath AOT. This "average-then-mask" strategy is in contrast to the "sample-then-average" strategy described in Sect. 2.3.

The results of this method provide a view of the features each sampling strategy can observe, and estimates of the mean AOT differences that are unbiased by scan angle artifacts. But it also represents a much richer data set than could be obtained from an instrument having similar retrieval capabilities to the full-swath MODIS but having only narrow or curtain sampling. As a result, this method reduces significantly the difference in AOT variability measured by the different sampling strategies compared to the difference obtained using the "sample-then-average" method. This reduction in the variability is illustrated also in Fig. 4 for the "average-then-mask" approach (red lines). It is clear that in the global, annual mean, the AOT for the sub-samples generally differs from the full-swath value by much less than 0.01 . However, the "average-then-mask" approach for the curtainlike cases provides spatial sampling that is much greater than would ever be acquired by an actual curtain instrument, because the aggregated samples come from different parts of the broad MODIS swath. So although this approach minimizes the view-angle bias, it includes far more of the broadswath data than would be available from a curtain instrument.

\subsubsection{An illustration of the average-then-mask sampling approach}

Using the "average-then-mask" method, we emphasize the issue of observability further in Fig. 7, where we zoom in on the key aerosol features in the region surrounding the tropical Atlantic Ocean, focusing on the seasonal AOT for the period July-August-September 2010. We show the MODIS full-swath seasonal mean AOT at grid cells both where C1 and $\mathrm{C} 3$ do and do not observe (i.e., the union of the two $\mathrm{C} 1$ sampling images, Fig. 7a and c, yields the full-swath seasonal mean for this region, as does the union of the two $\mathrm{C} 3$ sampling images, Fig. $7 \mathrm{~b}$ and d). Here the spatial gaps in the curtain-like sampling become more apparent, and visual 

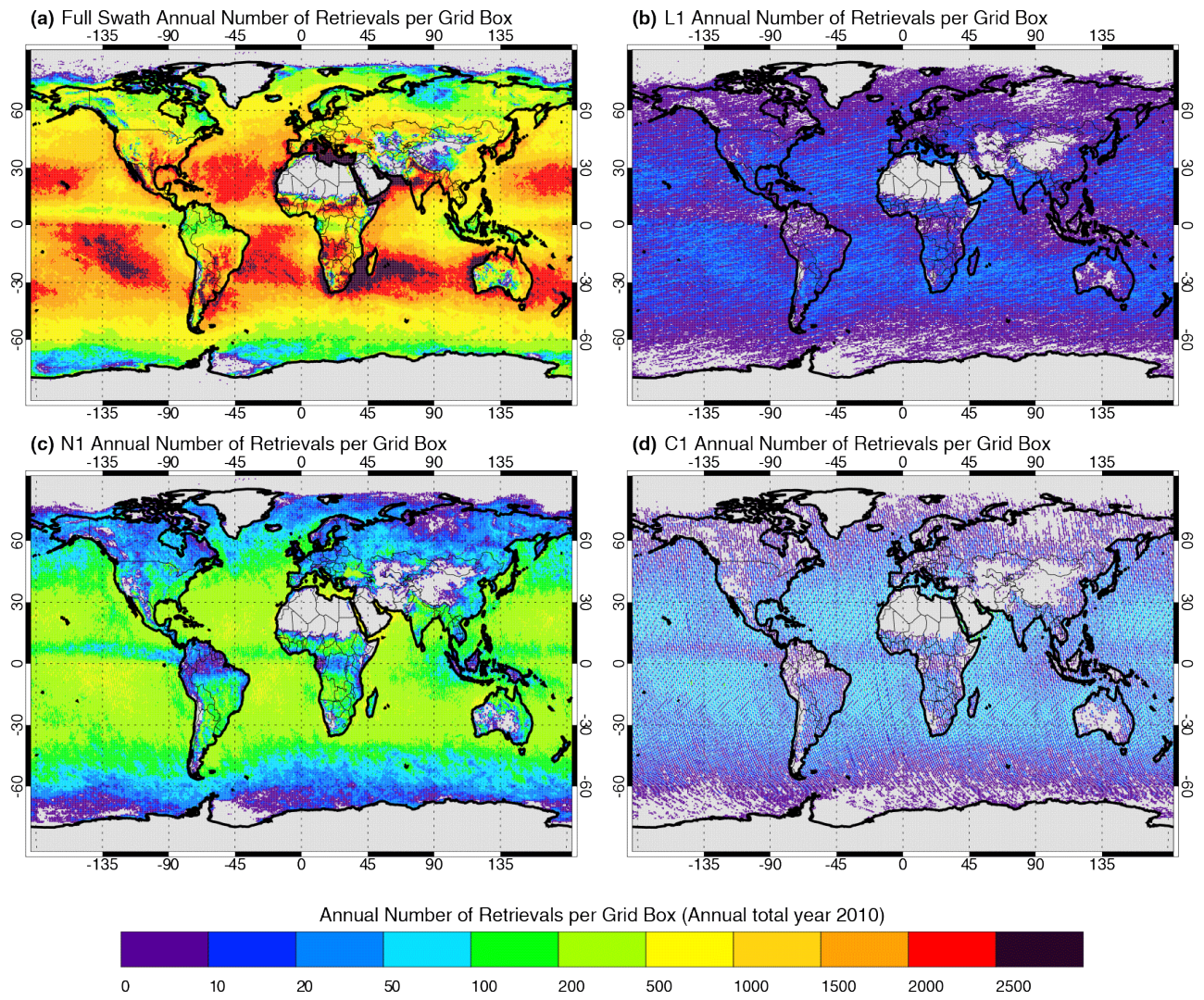

Figure 6. Number of MODIS Aqua AOT retrievals made per $0.5^{\circ} \times 0.625^{\circ}$ grid box for the entire year 2010 as used to compose the (a) full-swath annual mean shown in Fig. 3a and for the (b) L1, (c) N1, and (d) C1 sub-samples. Light grey shading indicates locations where no retrievals were available.

inspection of the figures reveals differences in the patterns of the aerosol features seen. For example, the AOT features over the Nile River valley are nearly absent in the $\mathrm{C} 1$ and $\mathrm{C} 3$ sampling (Fig. 7a and b) but are readily apparent when looking at the grid cells unobserved by these sampling strategies (Fig. 7c and d). Likewise, the biomass burning plume over South America is more structured, and has a much greater range of values, for the grid cells unobserved by $\mathrm{C} 1$ and $\mathrm{C} 3$ (again, Fig. 7c and d). Most readily apparent is the wide equatorial belt over the ocean, encompassing the Saharan dust plume, where the $\mathrm{C} 3$ sampling is almost completely absent due to glint (Fig. 7b versus d). Even for the $\mathrm{C} 1$ sampling, where the ocean glint is not an issue in this case, the South African biomass burning plume is also missing some of the highest-AOT regions when the observed and unobserved grid cells are compared (Fig. 7a and c).

A similar analysis is presented in Fig. 8 over the Asian region for the March-April-May 2010 seasonal average. Here we show only the $\mathrm{C} 1$ sub-sample masking. Aerosol features over Iraq, Iran, Turkmenistan, Afghanistan, northern China, and the Sichuan Basin in central China are almost completely unobserved by the $\mathrm{C} 1$ sampling (Fig. 8a), the seasonal AOT maxima and minima are lost, and the pattern of the main Asian outflow over the northern Pacific is less well defined.

\subsubsection{The $\triangle$ AOT spatial sampling artifact in seasonal-regional analysis}

For AOT trend and regional climate impact studies, quantitative differences matter. We assess the quantitative differences produced by different sampling strategies for several regions exhibiting major aerosol features as highlighted with white boxes in Figs. 7 and 8. We introduce a diagnostic metric, $\triangle$ AOT, which we call the AOT spatial sampling artifact. For a given spatial and temporal average, $\triangle \mathrm{AOT}$ is the spread in the spatiotemporal mean AOT among all of the sampling strategies considered. So, for each of the regions highlighted in Figs. 7 and 8, we compute the "averagethen-mask" seasonal-regional mean AOT for our time series for all of the along-track sampling strategies considered. $\triangle \mathrm{AOT}$ is then the difference between the maximum and minimum value among the sampling strategies for each seasonal-regional point:

$\Delta \mathrm{AOT}=\tau_{\max }-\tau_{\min }$

Because the glint significantly impacts the sampling in the $\mathrm{C} 3$ and N3 sub-samples for certain regions, we exclude those sub-samples from the $\triangle \mathrm{AOT}$ calculation in all cases (i.e., $\triangle \mathrm{AOT}$ is determined from the remaining eight sampling 

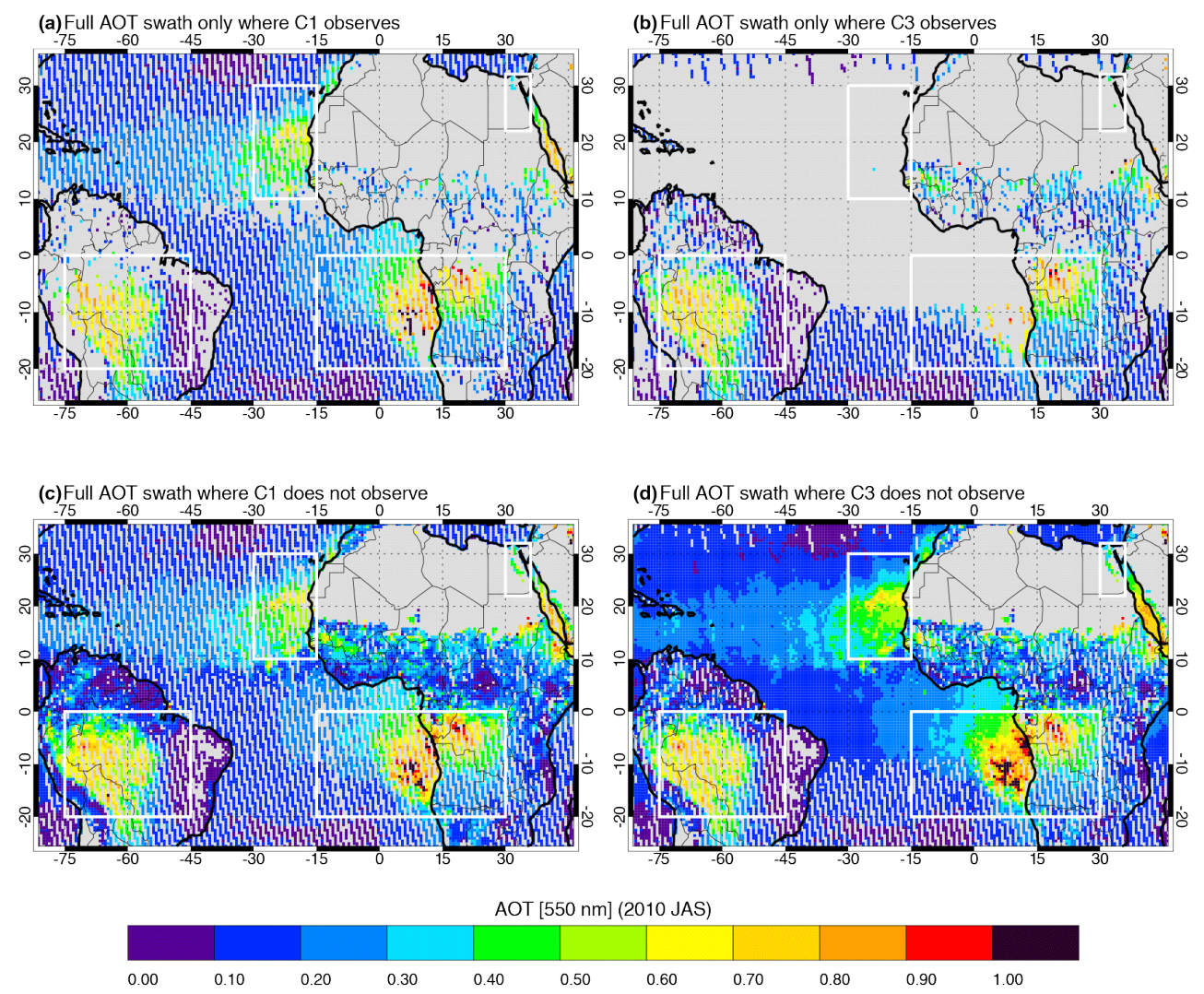

Figure 7. Full-swath seasonal (July-August-September 2010) MODIS Aqua AOT over the tropical Atlantic Ocean. The full-swath seasonal mean is masked to show only grid cells where the $\mathrm{C} 1$ and $\mathrm{C} 3$ sub-samples do (a, b) and do not (c, d) have a seasonal mean value. Figure $7 \mathrm{a}$ and $b$ illustrate the "average-then-mask" seasonal mean AOT. The white boxes outline regions discussed in the text.

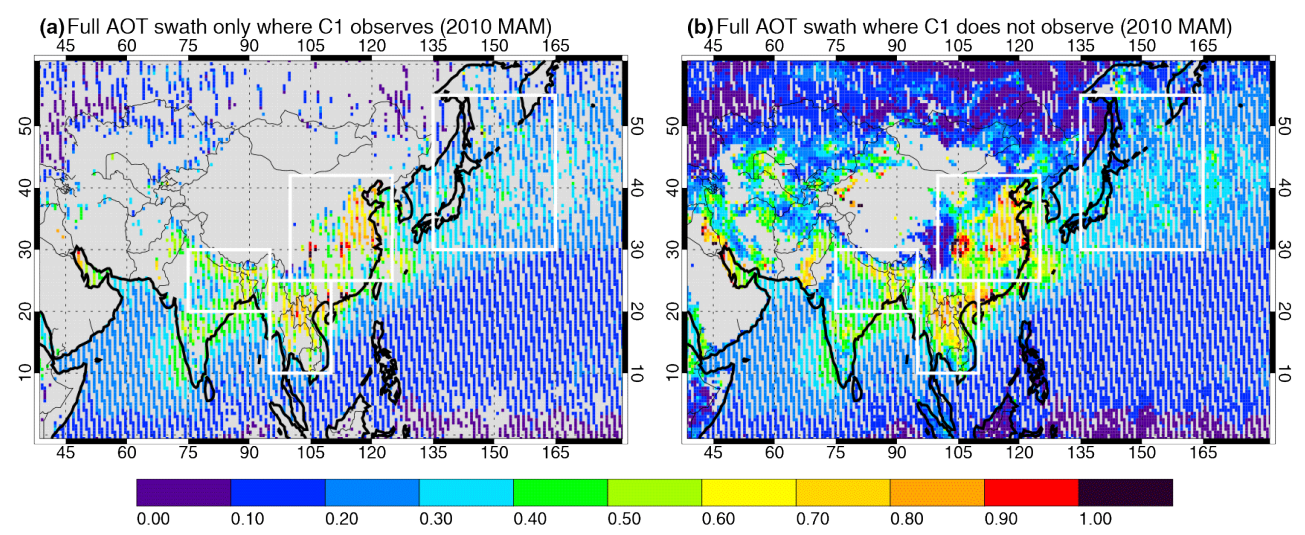

Figure 8. As in Fig. 7, but for the C1 sub-sampling mask for March-April-May 2010 over Asia. The full-swath seasonal mean AOT is shown both where the $\mathrm{C} 1$ sub-sample does (a) and does not (b) have a valid seasonal mean. The white boxes outline regions discussed in the text.

strategies). This restriction proves especially important for the southern Africa, African dust, Nile River, Southeast Asia, and Asian outflow regions, where glint would otherwise confound the results.

Figures 9 and 10 present, respectively, the $\triangle$ AOT spatial sampling artifacts for South America and the Indo-Gangetic Plain, two of the eight regions highlighted in Figs. 7 and 8 (the other regions, discussed here, are shown in the Supplementary material). We focus here on the along-track sampling artifact (red lines), and will discuss the results from other sampling approaches later in Sects. 2.5 and 3.2. To highlight the differences between curtain-like and narrowswath sampling, we also show the $\triangle \mathrm{AOT}$ for the full swath, $\mathrm{C} 1, \mathrm{C} 2$, and C4 samplings only (dotted red line) and for 


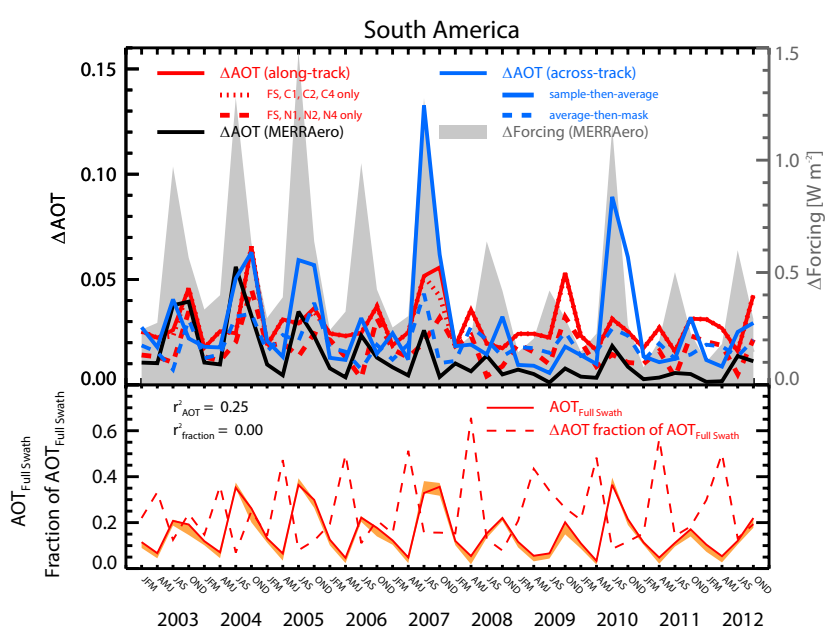

Figure 9. Seasonal-regional sampling artifacts $\triangle \mathrm{AOT}$ and $\Delta$ forcing for South America. Red lines are the MODIS along-track $\triangle$ AOT sampling artifact using the average-then-mask approach (solid: all samples except $\mathrm{C} 3$ and N3; dotted: full swath, C1, C2, and $\mathrm{C} 4$ samples only; dashed: full swath, N1, N2, and N4 samples only). Blue line is the MODIS across-track $\triangle$ AOT sampling artifact (solid for the "sample-then-average" approach, dashed for the "average-then-mask" approach). Black line is the along-track $\triangle$ AOT sampling artifact from the MERRAero results. Grey shading (corresponding to right-hand vertical scale) is the $\Delta$ forcing artifact from MERRAero results. Also shown are the MODIS full-swath mean AOT (bottom, solid line), the range of the along-track subsample AOT values about the full-swath mean (bottom, shading), and $\triangle$ AOT as a fraction of the full-swath AOT (bottom, dashed). Finally, we show the $r^{2}$ correlation coefficients between $\triangle$ AOT and the full-swath seasonal-regional mean AOT, as well as the $\Delta \mathrm{AOT}$ as a fraction of the full-swath mean.

the full swath, N1, N2, and N4 samplings only (dashed red line). For all, we additionally show the full-swath AOT value, the range of the sub-sample AOT values around the fullswath value, and the magnitude of $\triangle \mathrm{AOT}$ as a fraction of the seasonal-regional full-swath AOT. Finally, the $r^{2}$ correlation coefficient of the $\triangle \mathrm{AOT}$ with the full-swath AOT and the fraction of the full swath are also indicated.

We refer to $\triangle \mathrm{AOT}$ as the "sampling artifact", as it shows the uncertainty in the seasonal-regional AOT due to limited spatial sampling, relative to the full swath. We note that for all regions the $\triangle \mathrm{AOT}$ sampling artifact is highest for the curtain-like sampling (dotted red line), and so drives the sampling artifact when all sampling strategies are included (solid red line). We also emphasize that $\triangle \mathrm{AOT}$ as computed here is actually a lower bound on the possible AOT spatial sampling artifact. If additional along-track sampling strategies were considered they could possibly contribute to increasing the spread between the maximum and minimum seasonalregional AOT, but they would not reduce the spread over what already is computed.

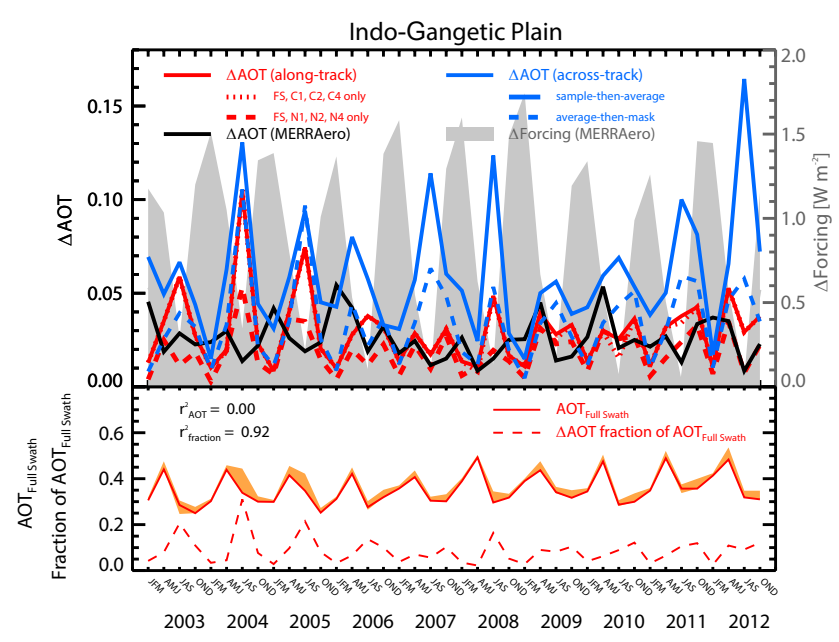

Figure 10. As in Fig. 9, but for the Indo-Gangetic Plain.

The South America region (Fig. 9) shows significant annual and inter-annual variability in the full-swath AOT, with a peak AOT of between 0.2 and 0.4 typically occurring in JulyAugust-September (JAS) or October-November-December (OND) associated with seasonal biomass burning. This peak is modestly correlated $\left(r^{2}=0.25\right)$ with the $\Delta$ AOT, which can be as high as 0.06 . Interestingly, $\triangle \mathrm{AOT}$ is uncorrelated with its fractional comparison to the full-swath AOT $\left(r_{\text {fraction }}^{2}\right.$ in bottom panel of Fig. 9, which is the correlation of bottom panel dashed red line and top panel solid red); although, as a fraction of the full-swath AOT the $\triangle$ AOT typically peaks at $40 \%$ and can be as high as $60 \%$. Thus, for South America, the uncertainty in AOT due to sampling may be as much as 0.06 , comprising $\sim 15 \%$ of a base magnitude as high as about 0.4 , and can also represent uncertainties as great as $60 \%$ in the regional AOT when AOT is lower.

Southern Africa (Fig. S1a in the Supplement) is another region affected by seasonal biomass burning, with peak AOT of about 0.4 occurring in JAS. The peak $\triangle \mathrm{AOT}$ is at most 0.03 and is weakly correlated with the full-swath AOT $\left(r^{2}=\right.$ 0.14 ), but much more strongly with the fractional contribution $\left(r^{2}=0.72\right)$.

For African dust (Fig. S1b in the Supplement) the $\Delta$ AOT is small (approximately 0.01) and is consistently less than about $5 \%$ of the magnitude of the full-swath seasonalregional AOT. In other words, for the African dust region, the average-then-mask sampling does not significantly impact these AOT statistics. For the Nile River (Fig. S1c in the Supplement) the $\triangle \mathrm{AOT}$ is at most about 0.05 and is modestly correlated $\left(r^{2}=0.37\right)$ with the full-swath seasonal-regional mean AOT signal. The full-swath mean AOT has a seasonal signal, varying between about 0.2 and 0.4 in magnitude, and the sampling artifact may be as much as about $20 \%$ of the full-swath value.

Turning to Asia, for the Indo-Gangetic Plain (Fig. 10), the peak values of $\triangle \mathrm{AOT}$ are as high as 0.1 but are uncorrelated 
with the full-swath AOT, which itself peaks in magnitude at about 0.5 . The sampling artifact may thus be as much as about $30 \%$ of the full-swath signal. In China (Fig. S1d in the Supplement) the $\triangle \mathrm{AOT}$ is as high as 0.09 and is sometimes as large $20 \%$ of the full-swath mean AOT, which itself varies between about 0.3 and 0.6 in magnitude. In the Southeast Asia (Fig. S1e in the Supplement) and Asian outflow (Fig. S1f in the Supplement) regions the peak $\triangle$ AOT values are 0.05 and 0.015 , respectively. For Southeast Asia, this sampling artifact can be as large as $20 \%$, but is mostly less than $10 \%$ of the full-swath signal. The contribution to the Asian outflow signal is negligible, with sampling introducing an uncertainty of only about $5 \%$ at most for a full-swath AOT that peaks above 0.4 in magnitude.

In summary, with the "average-then-mask" approach, differences presented are due solely to sampling, as we are only comparing the gridded full-swath seasonal mean values with sub-samples of itself, and cross-swath anomalies are implicitly removed by the averaging. This "average-thenmask" approach incorporates much greater sampling than actual reduced-swath instruments can obtain - about three-tofour times more samples for the narrow-swath, and about 16 times more samples for the curtain. Nevertheless, significant qualitative and quantitative differences still appear in the seasonal-regional average AOT distributions; minima and maxima do not capture the extreme values, and some regional features are entirely missed. Due to the much greater sampling included in the "average-then-mask" data, results presented in Figs. 4, 9, 10, and S1 in the Supplement are significantly more favorable than would be produced for real instruments having such spatial sampling characteristics, and thus the sampling artifacts presented in this section are effectively lower bounds. The overall magnitude of the sampling artifact is largest for the curtain-like sub-samples, as might be expected. The nature of this artifact is such that in some regions (South America, Indo-Gangetic Plain, China) it can be as large as $20-60 \%$ of the full-swath AOT signal or as great as 0.1 in AOT magnitude.

\subsubsection{Along-track sub-sampling and trends in aerosol optical thickness}

In the previous section, we showed artifacts that are introduced in the seasonal-regional mean AOT when the fullswath data are sub-sampled. Here we investigate how spatial sampling affects the ability to detect statistically significant AOT trends.

Our approach follows the trend analysis presented in Zhang and Reid (2010), which employs the statistical tools of Weatherhead et al. (1998) to assess confidence levels in the derived trends. Briefly, a linear model is fit to the monthly mean AOT time series at a grid box. A first-order autoregressive "noise" model characterizes the residual of the observed time series from the linear model. The slope of the linear fit, $\omega$, is the trend in the time series, and the standard deviation of the trend, $\sigma_{\omega}$, is defined in terms of the variance of the residual noise model (see Eq. 2 in Weatherhead et al., 1998). Where the ratio $\left|\omega / \sigma_{\omega}\right|>2$, the trend is statistically significant at the $95 \%$ confidence level (Weatherhead et al., 1998).

AOT trends and statistical significance maps are produced for our 10-year time series of MODIS AOT data. As in Zhang and Reid (2010), the AOT monthly mean time series is deseasonalized before the linear model is fit, because the seasonal aerosol signal is so large in many parts of the world. We considered the trends both in terms of the monthly means composed from our "average-then-mask" and "sample-thenaverage" methodologies. In Figs. 11 and 12, we show the "sample-then-average" trends and statistical significance, respectively, for the MODIS full swath and several of our subsamples. The "sample-then-average" method more realistically represents the data that would be acquired by a narrowswath or curtain instrument, but is subject to the uncertainty associated with the MODIS view-angle artifact, and so may contain scan angle biases in the AOT field itself that could alias the magnitude of the derived AOT at some locations. However, this will not affect the statistical significance of the derived trends as long as whatever scan angle artifacts exist do not vary over time for a given sub-sample of the MODIS swath. The high calibration stability of the MODIS instruments (Xiong et al., 2006) supports this assumption, although a calibration drift in certain MODIS channels does affect the Collection 5 MODIS AOT data that has since been corrected for Collection 6 (Levy et al., 2010, 2013). For the purpose of the current study, we are concerned primarily with differences in the statistical significance of the trends that can be derived for various distributions of samples.

Figure 11 shows the AOT trend for several of our sampling approaches. The full swath (Fig. 11a) shows a strong negative trend in AOT over the Amazonian region in South America, in Siberia north of Mongolia, and across Alaska, and moderate negative trends across the eastern United States and Canada and the western North Atlantic Ocean, Europe and the Mediterranean, in the Gulf of Guinea and off the west coast of northern Africa, and in the western Pacific around the Maritime Continent. Strong positive trends are apparent in the Arabian Sea, across India, and in the Bay of Bengal, in Iraq, off the western coast of southern Africa, across Sudan and Ethiopia, near Beijing in eastern China, in eastern central Argentina, and in eastern Siberia and across the northern Pacific Ocean. Moderate positive AOT trends are seen in the western United States and Canada, over southern Africa, and more generally across northern Asia. Except as noted previously, the oceans generally have no trend in AOT or else a weakly positive trend. The locations and signs of our computed trends are generally similar to Zhang and Reid (2010, their Fig. 7a). Our trends differ from theirs primarily in the Pacific west of Mexico, where we show a slight positive trend and they show a weak negative trend, and as well in the western Pacific and near the Maritime Continent where they find a weak positive trend and we find a weak negative trend. We 

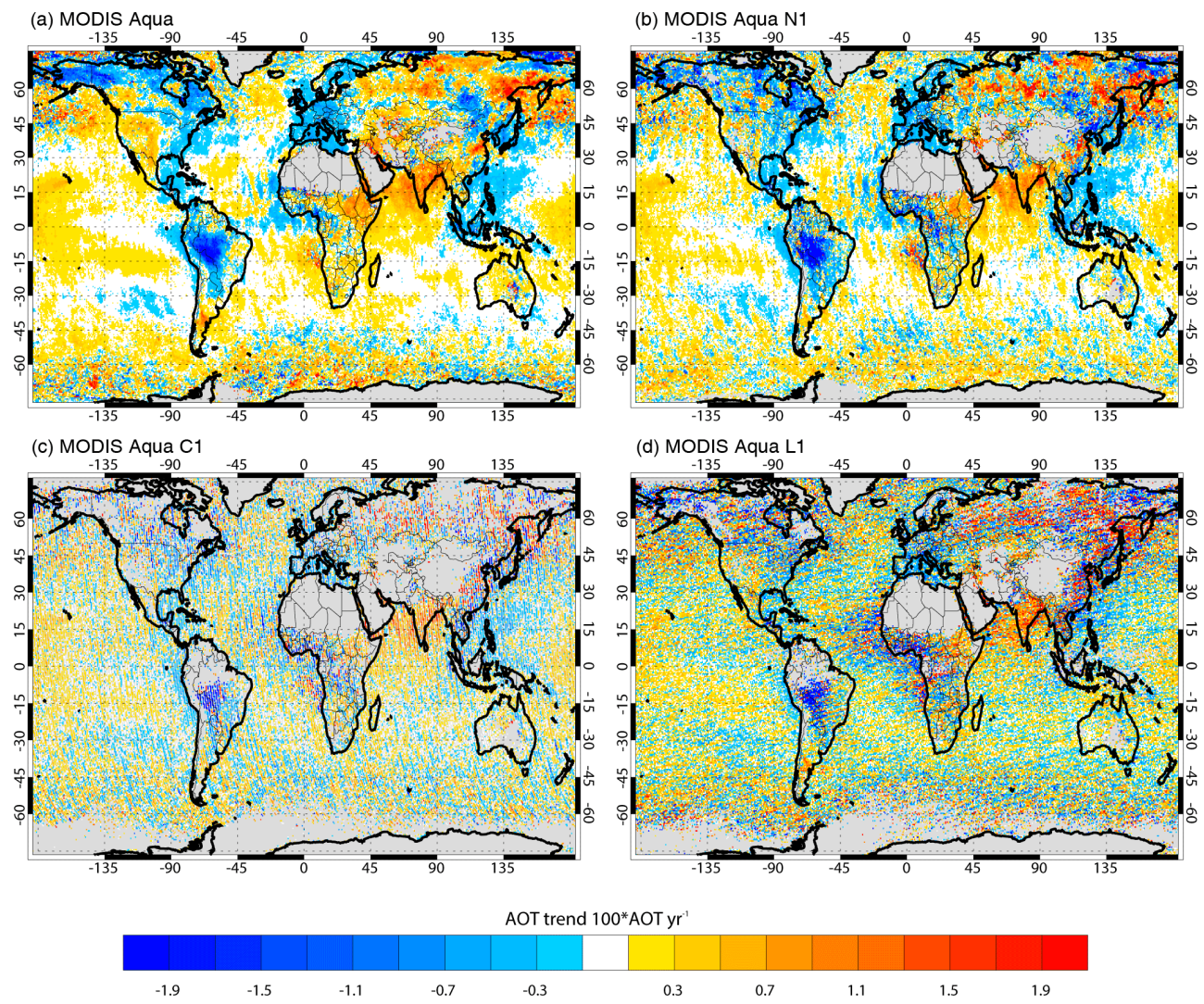

Figure 11. Trend for the 10-year (2003-2012) time series of MODIS Aqua AOT. We show the trend for the (a) full swath, (b) N1, (c) C1, and (d) L1 samplings. Grey areas are locations with either no valid retrievals or where the time series has fewer than 12 month $_{n}$ and month $_{n-1}$ pairs.

note that Zhang and Reid (2010) restricted their analysis to over-ocean regions only, derived trends from a different time series (2000-2009), and used their "assimilation-grade" version of the MODIS AOT product, which is quality controlled as described in Zhang and Reid (2006), and so is a somewhat different data set than considered here.

The N1 sampling trends (Fig. 11b) are also similar in pattern and sign to the full-swath trends, but differences from the full swath are more clearly visible, including a stronger positive trend associated with the southern African biomass burning plume and a more strongly negative trend across central western Africa and in northeastern Asia. The lesser coverage associated with the $\mathrm{C} 1$ sampling makes the trends harder to discern for that case (Fig. 11c), although the overall patterns of increasing and decreasing trends are again fairly consistent with the full swath. The other narrow and curtain-like samples have similar trend patterns and magnitudes (not shown), but differ in detail, and the N3 and C3 samples have poor coverage over the tropical oceans. We also considered the mid-width (MW) sampling trend (not shown), finding it to be similar in behavior to the full-swath trends. (The acrosstrack L1 sampling trend will be discussed in Sect. 2.5.)
The differences in the trend magnitudes between our sampling approaches are not unexpected. Zhang and Reid (2010) found, for example, weaker magnitude for trends from MISR observations than for MODIS, and attributed this difference at least in part, if not entirely, to the lower spatial coverage of MISR. Additionally, our "sample-then-average" approach can affect the magnitudes of the trends, due to MODIS viewangle biases discussed previously. Our focus is thus on our ability to assign statistical significance to whatever trends appear in the maps.

In Fig. 12 we present the spatial distribution of statistical significance for the trends shown in Fig. 11. For the full swath (Fig. 12a) our analysis shows that the computed trends are significant at the $95 \%$ level broadly across the tropical Pacific Ocean, in the Arabian Sea and Bay of Bengal, in the Mediterranean, and then across Sudan and Ethiopia and into the western Indian Ocean. Our patterns for significance are again very similar to those of Zhang and Reid (2010) (their Fig. 7b), except that their broad region of significance between southern Africa and South America is much less pronounced in our analysis. Over land we find statistical significance in the full swath for southern India, near Beijing, 

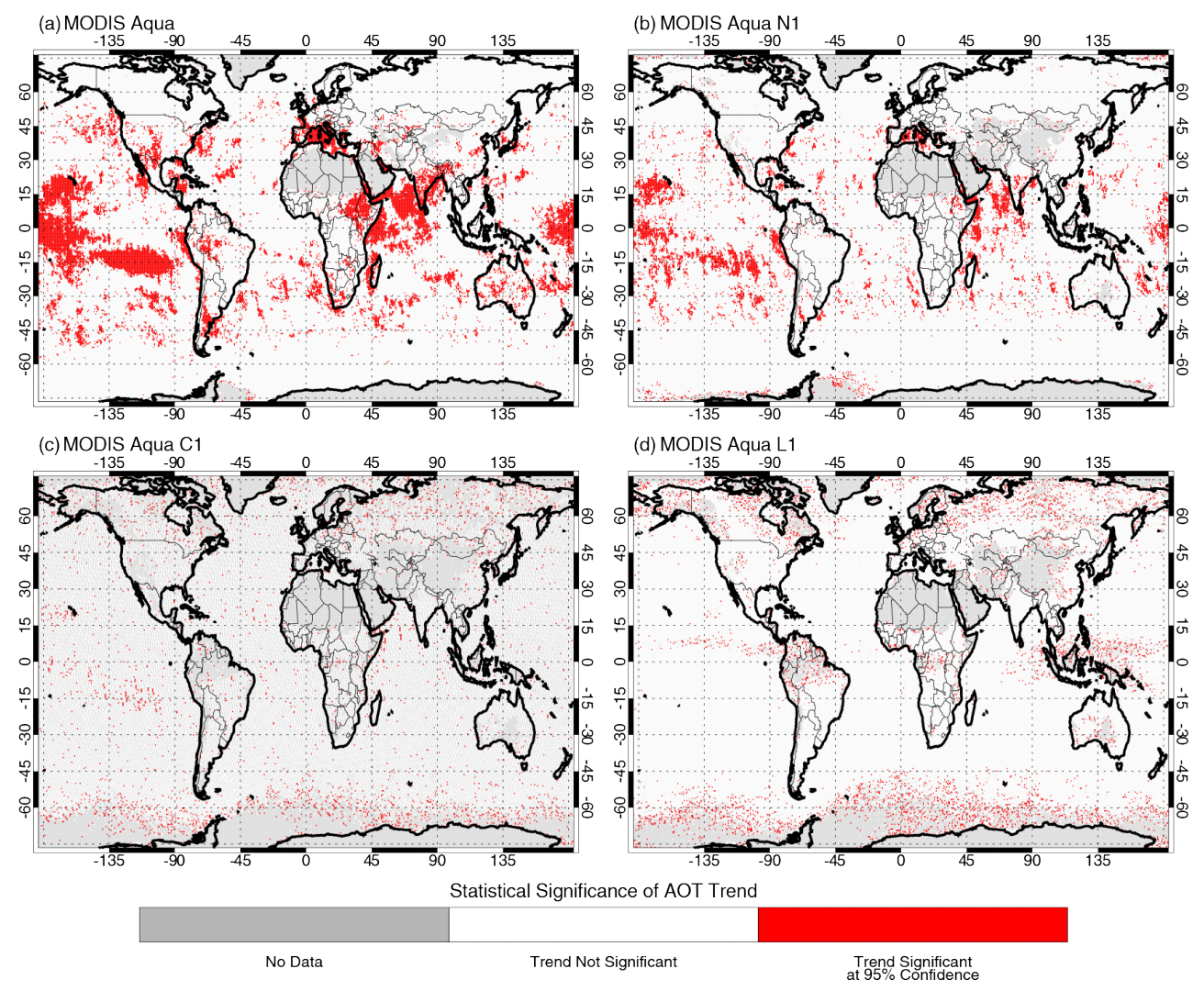

Figure 12. As in Fig. 11, but showing the statistical significance for the trends shown in Fig. 11. Regions colored red show regions with statistically significant trends at the $95 \%$ confidence level.

across the central United States, in Argentina, and across portions of the biomass burning region in Amazonia.

For the MW sampling (not shown) the over-ocean patterns of significance are nearly identical to the full swath, but over land there are notable differences, with MW indicating no significance in the derived trends over Amazonia, in China, or in the central United States. The regions of significance in the trends over India and in the Sudan and Ethiopia region are also much reduced in area. This reduction in areal extent of significance patterns worsens for the N1 sampling (Fig. 12b), with significance essentially gone over Sudan and Ethiopia, and as well being much reduced over Argentina. The patterns over ocean are still generally similar to the full swath, but the individual regions are less coherent. For the $\mathrm{C} 1$ sampling (Fig. 12c), the statistical significance at the $95 \%$ confidence level is essentially gone, with nothing identifiable over Sudan, Ethiopia, India, or Argentina, sparse identification of significance over other land area (especially at high northern latitudes), and only a hint of significance in the tropical Pacific and in a few other ocean regions. The patterns of significance for the other narrow and curtain-like samplings (not shown) are similar to the $\mathrm{N} 1$ and $\mathrm{C} 1$ shown in Fig. 12, respectively, though different in detail. $\mathrm{N} 2$ and $\mathrm{C} 2$ have somewhat better coverage over the oceans. N3 and C3 - again, because of the glint - show poor coverage over the oceans. $\mathrm{C} 3$ in particular has far worse coverage over the ocean than $\mathrm{C} 1$. Although the reduction in spatial sampling reduces the number of grid cells in which statistical significance can be identified versus the full swath, it is possible that at least in broad regions - for sufficient averaging areas - we can nevertheless obtain statistically significant trends even for the curtain sampling. We address this quantitatively in the next sub-section.

For comparison, the trends and statistical significance were also computed from monthly means constructed using our "average-then-mask" method. Recall that this provides far greater sampling than the actual along track sampling would provide. The patterns, signs, and magnitudes of the trends (Fig. S2 in the Supplement) are quite similar to those shown in Fig. 11. The effect of the more favorable "averagethen-mask" approach is most notable for the patterns of statistical significance (Fig. S3 in the Supplement), which are broadened considerably for the $\mathrm{N} 1$ and $\mathrm{C} 1$ samples in this approach. Still, considerable spatial sampling gaps remain, especially over India, the Arabian Sea, Sudan and Ethiopia, Brazil, and the central US, where statistical confidence in the derived trends is not assured in the narrower samplings. 


\subsection{Across-track sub-sampling results}

The recent paper by Geogdzhayev et al. (2013) is of particular relevance to this study, as they provided a similarly motivated analysis of the MODIS AOT data. Their approach was to develop sub-samples by aggregating individual scans across the MODIS swath. They argued that averaging across the MODIS swath removed the view-angle artifact when compared to the full set of MODIS observations, versus a comparison to along-track sampling (i.e., samples similar to our C1-4 sub-samples).

We implemented this sampling approach in the same framework as the along-track samplings discussed earlier, selecting five evenly spaced across-track sub-samples (L1, L2, L3, L4, and L5, with the "L" standing for "latitudinal", see Fig. 2b). The year 2010 annual mean AOT for the L1 sub-sample is shown in Fig. 13. When compared with the full-swath annual mean AOT (Fig. 3a), we see a lot of "noise" (small-scale variability) in the AOT field for the L1 sub-sample. Consistent with the earlier discussion of our along-track sub-samples, there are important aerosol features missed by this sampling, including the South American biomass burning plume and the Russian fires. Nevertheless, when the global, annual mean AOT is compared to the fullswath AOT, there is essentially no difference between any of the latitudinal sub-samples and the full swath (Fig. 4, blue lines). The annual means shown in Fig. 4 are for the "samplethen-average" methodology applied to this data set. Our result is consistent with Geogdzhayev et al. (2013), who also used the "sample-then-average" methodology. Even though this approach was shown not to work so well for alongtrack sampling (grey lines in Fig. 4), we find that if anything there is less variability among the sub-samples for the across-track sub-sampling than for the along-track with the "average-then-mask" approach applied (i.e., spread in blue lines is smaller than the spread in the red lines in Fig. 4). When the "average-then-mask" approach is applied to the across-track samplings the spread in the global, annual mean AOT collapses even further.

When considering the seasonal-regional statistics, however, it is clear a spatial sampling artifact still remains in the across-track sampling, as might be expected from the smallscale variability in the map of global AOT (Fig. 13). Figures 9, 10, and S1 in the Supplement includes the acrosstrack $\triangle$ AOT spatial sampling artifact, which can be directly compared to the along-track results discussed earlier. Both the "sample-then-average" and "average-then-mask" variants of this are shown for the across-track sampling. In general, the "average-then-mask" across-track sampling artifact is similar in magnitude to the along-track values, in some regions on average less and in others on average greater. In all regions, however, there are comparable magnitude spikes in this sampling artifact. By contrast, the "sample-then-average" across-track sampling artifact is typically much larger than the along-track or across-track

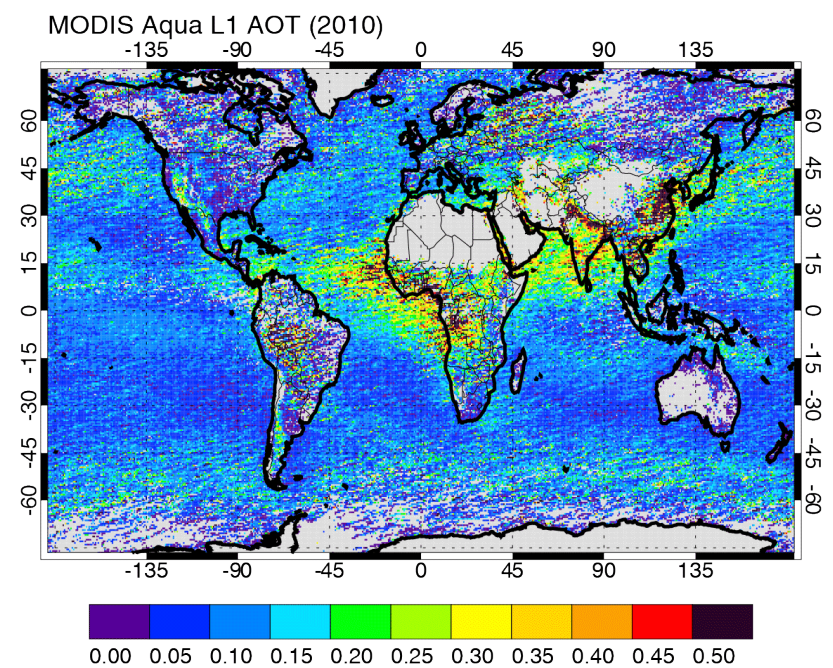

Figure 13. As in Fig. 3d, the year 2010 annual mean AOT gridded at $0.625^{\circ} \times 0.5^{\circ}$ horizontal resolution for the L1 across-track MODIS sampling.

"average-then-mask" values, corresponding to its relatively poorer spatial coverage.

In Figs. 11d and 12d we show, respectively, the AOT trend and statistical significance pattern for the L1 across-track sub-sample. The global distribution of the sign of the trends is generally consistent with the full-swath data set (Fig. 11a), but there are considerable differences in coverage. The fullswath observations have hundreds-to-thousands of observations per year informing a given grid box (Fig. 6a), whereas the L1-type sampling has at most a few dozen (Fig. 6b). The relatively poor coverage for the L1 sampling at this resolution renders the trend statistically insignificant almost everywhere (Fig. 12d). This is also true for the other latitudinal sub-samples (not shown). The particular areas of coverage and trend magnitudes differ somewhat among the different latitudinal sub-samples, but in all cases there is almost no ability to assign statistical significance. The result is the same when the "average-then-mask" approach is applied to calculating the trend (Fig. S2d in the Supplement) and significance (Fig. S3d in the Supplement).

For completeness, we performed this same trend analysis at a coarser $10^{\circ} \times 10^{\circ}$ spatial aggregation, compatible with the resolution of the analysis performed in Geogdzhayev et al. (2013). Here, the sampling of the MODIS data is performed on the coarse resolution grid, monthly means are formed, and the trends are calculated. The AOT trends and the map of $95 \%$ statistical significance for the full swath, L1, N1, and C1 samplings are presented in Figs. 14 and 15, respectively. Results may be compared with Figs. 11 and 12. The trend magnitude and sign at the coarser aggregation resolution are qualitatively similar to those derived at the higher aggregation resolution, and at the coarse resolution the trends across the sub-samples are generally similar to one 

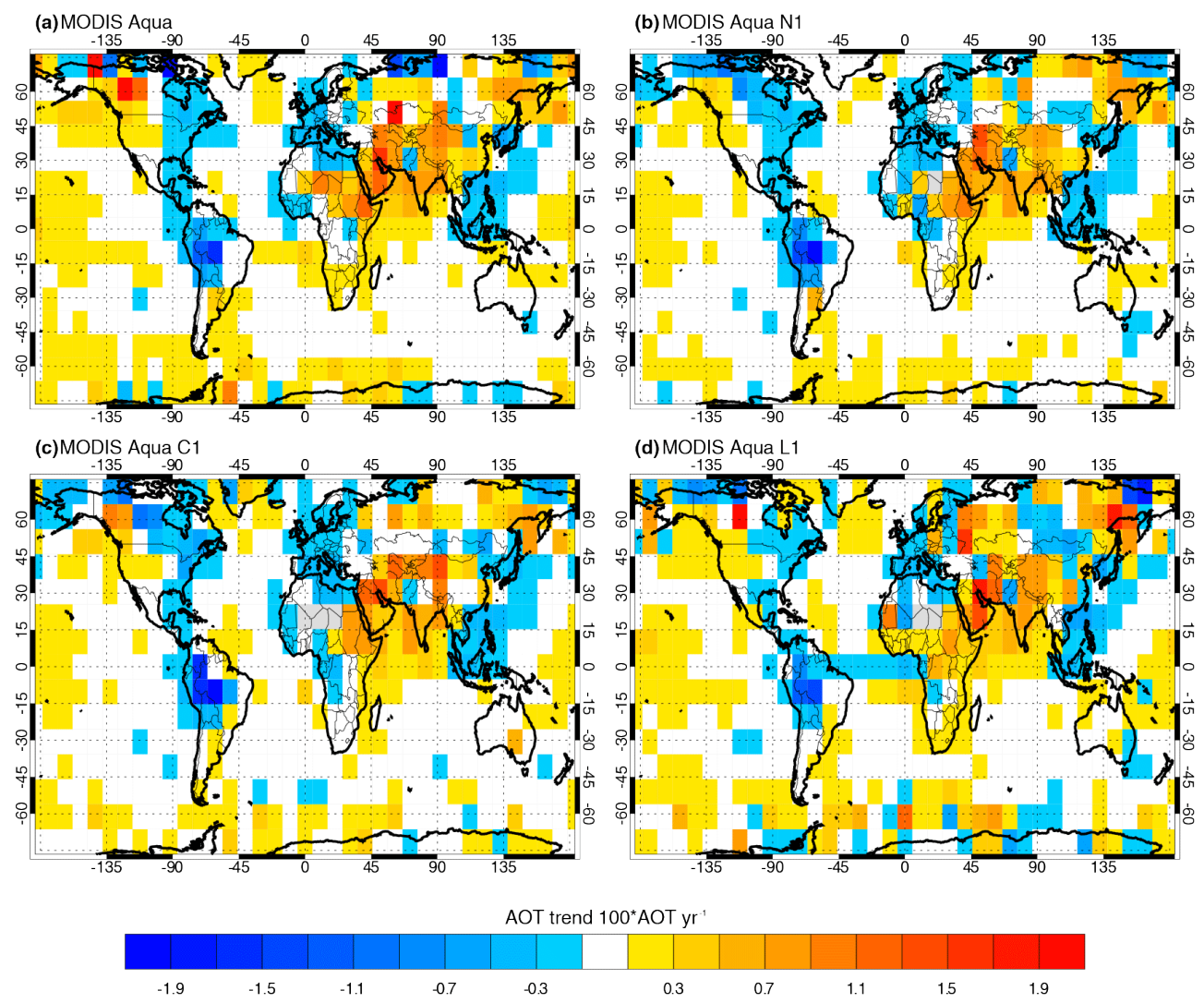

Figure 14. Aerosol trends for the (a) full swath, (b) N1, (c) $\mathrm{C} 1$, and (d) $\mathrm{L} 1$ samplings at $10^{\circ} \times 10^{\circ}$ aggregation resolution.

another. The assignment of significance to a detected trend is of course statistically more robust at the coarser spatial resolution, since relatively more of these larger grid boxes have valid monthly means at the coarser spatial resolution. Thus, unlike what was seen at higher spatial resolution (Fig. 12c and $\mathrm{d}$, respectively), at $10^{\circ} \times 10^{\circ}$ spatial resolution it is possible to assign statistical significance more broadly for the $\mathrm{C} 1$ and L1 samples (Fig. 15c and d). Using the more favorable "average-then-mask" approach, the coarse resolution aggregated trends (Fig. S4 in the Supplement) and statistical significance (Fig. S5 in the Supplement) are even more alike across the sub-samples.

\section{Spatial sampling of a global aerosol transport model}

In analyzing spatial sampling issues in the context of the MODIS AOT data set, as was done in Sect. 2, instrumental and algorithmic artifacts in the data set contribute uncertainty to our conclusions. To that end, we seek to also apply our analysis machinery to a data set that is as independent as possible from the MODIS product. It seems natural, then, to investigate these issues in the context of a global aerosol transport model, where - whatever its shortcomings - at least it is not impacted by, e.g., view-angle artifacts, calibration drift, sun glint, or even - necessarily - clouds. However, we must also consider that an aerosol transport model presents issues of its own. There is a considerable literature within the AeroCom community, for example, that documents the performance and biases with current aerosol transport models (e.g., Textor et al., 2006; Kinne et al., 2006; Schulz et al., 2006; Huneeus et al., 2011; Myhre et al., 2013; Stier et al., 2013; Randles et al., 2013). To the issues explicitly called out in those references, we add that the ability to represent aerosol spatial and temporal variability on scales smaller than 100 s of kilometers and months in time is particularly relevant to the question being addressed here. Climate models with grid boxes several 100s of kilometers in size seem to us not to be the appropriate tool. Fortunately, we have access to a recent aerosol reanalysis produced in a relatively high spatial resolution global aerosol transport model. Although we cannot here resolve all the possible issues in applying this aerosol reanalysis to our question, or for that matter provide a comprehensive validation of the reanalysis, we hope that we offer sufficient confidence to proceed with our central question.

\subsection{The GEOS-5 MERRA aerosol reanalysis (MERRAero)}

The NASA Goddard Earth Observing System Model (GEOS-5) is an Earth system model maintained by the 

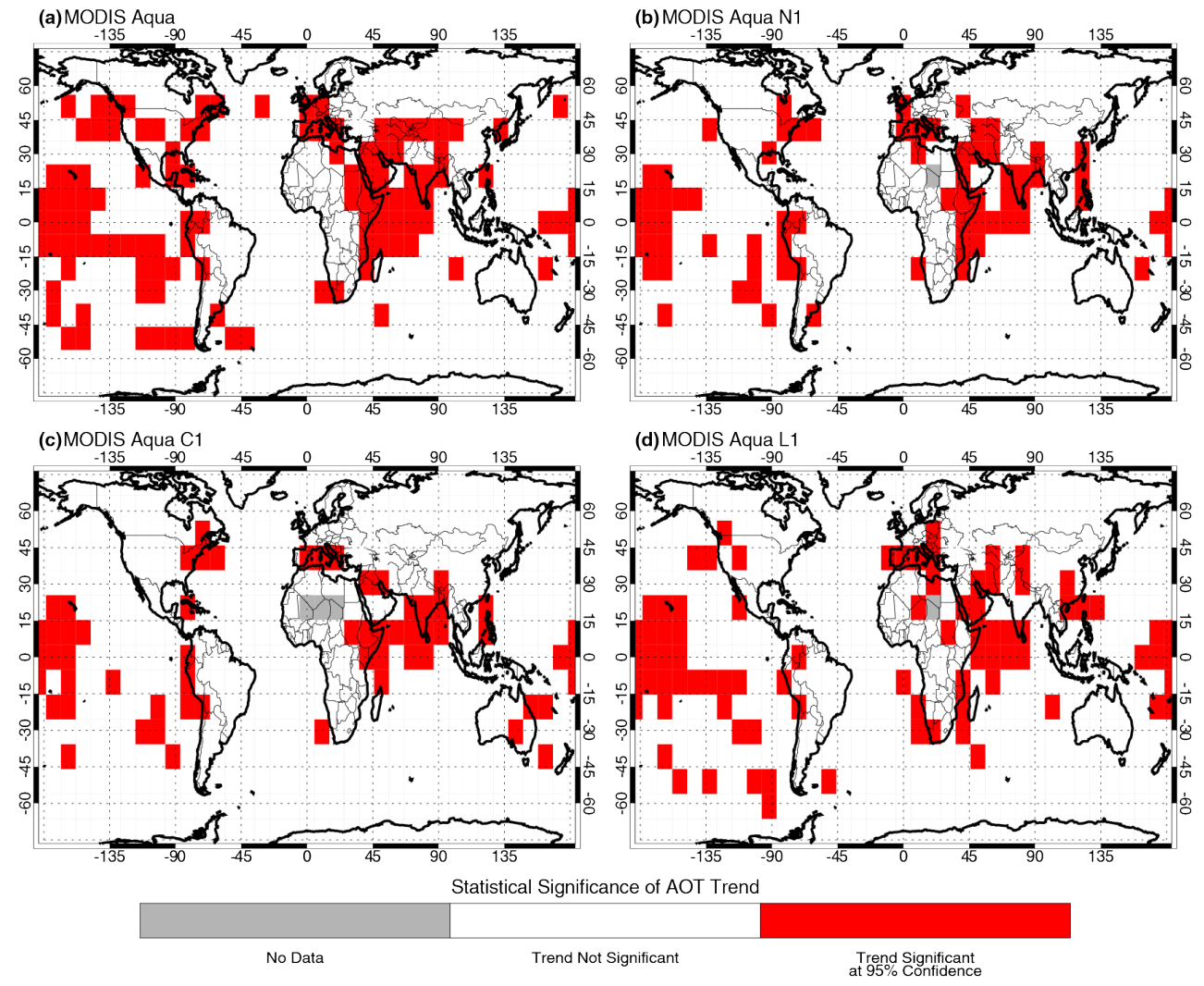

Figure 15. As in Fig. 14, but for the $95 \%$ statistical significance interval.

NASA Global Modeling and Assimilation Office (Rienecker et al., 2008). GEOS-5 contains components for atmospheric and oceanic circulation, land surface processes, ocean biogeochemistry, radiation, and atmospheric composition and chemistry. An aerosol module derived from the Goddard Chemistry, Aerosol, Radiation, and Transport (GOCART, Chin et al., 2002) model has been incorporated in the GEOS system (Colarco et al., 2010). The GOCART module treats the life cycles - including sources, sinks, and chemistry - of tropospheric sulfate, carbonaceous, dust, and sea salt aerosols as a series of non-interacting tracers (see the Supplement).

In addition to functioning as an Earth system model, a primary focus of GEOS-5 itself is as a tool to provide reanalyses to NASA instrument teams and the broader scientific community. The present atmospheric reanalysis performed in GEOS-5 is the Modern-Era Retrospective Analysis for Research and Applications (MERRA, Rienecker et al., 2011), which provides a global, three-dimensional $\left(0.5^{\circ} \times 0.666^{\circ}\right.$ latitude by longitude, 72 vertical levels from the surface to approximately $85 \mathrm{~km}$ ), six-hourly atmospheric reanalysis for the period 1979-present. Augmenting MERRA is our own aerosol reanalysis, so-called MERRAero, covering the period 2002-present. MERRAero is a "replay" of the GEOS-5 system driven by the MERRA atmospheric fields, with the GOCART aerosol module run online within the system, and including assimilation of AOT derived from MODIS Aqua and Terra (Kessner et al., 2013; Buchard et al., 2014; Sessions et al., 2014). The AOT data assimilated in MERRAero are not the MODIS Collection 5 aerosol retrievals themselves, but rather result from a neural network regression of the Collection 5 reflectances to independent AOT measurements from the Aerosol Robotic Network (AERONET, Holben et al., 1998), a ground-based, global network of sun photometers (see the Supplement). The global, annual mean of this derived "data assimilation " (DA) grade MODIS Aqua AOT that is assimilated in MERRAero is shown in Fig. 4 (dashed green line), and is quite obviously lower in magnitude than the MODIS Collection 5 AOT (e.g., red and blue lines), in part due to the more conservative cloud clearing being applied. For comparison, Zhang and Reid (2010) also show a lower magnitude for their DA grade version of the MODIS AOT data set than is found for the operational MODIS retrieval algorithms.

MERRAero is run globally at $0.5^{\circ} \times 0.625^{\circ}$ latitude by longitude horizontal spatial resolution, and we analyze the period 2003-2012, to cover the same analysis period applied to the MODIS data. We look at the AOT simulated in MERRAero, and although this AOT has an imprint of MODIS information on it due to the aerosol assimilation, 
we draw from the model the simulated AOT immediately prior to the aerosol assimilation step, which means that effectively we are looking at model AOT fields that have not seen the MODIS information for approximately $24 \mathrm{~h}$. Overall, MERRAero has an AOT bias with respect to AERONET of -0.022 , an RMS error of 0.148 , and an $r^{2}$ correlation coefficient of 0.629 . These statistics are improved over versions of the model that do not invoke aerosol assimilation. Further description and evaluation of the MERRAero system and the aerosol assimilation methodology are a work in progress (see also the Supplement).

\subsection{Results of sampling analysis}

The gridded nature of the model fields lends itself to a somewhat different approach to sub-sampling than was developed for the MODIS retrievals. We use an orbital sampling extension to the OpenGrADS software package (http://opengrads. org/doc/udxt/orb/orb.html) which exploits the readily available two-line element (TLE) orbital parameters from a wide array of operational spacecraft in order to develop an orbital masking tool. This orbital mask is "flown" through the gridded model output, and a number of different sub-samples are accumulated. Figure $2 \mathrm{c}$ illustrates how this is applied to sampling MERRAero fields for a single orbit along the Aqua track (a MODIS-like full swath, a MISR-like narrow swath, and a CALIPSO-like "curtain" track), as well as for an orbit of the approximately parallel nearby Aqua spacecraft (a narrow swath and a "curtain" track). Note that the operational TLE is not used in this package, but rather a canonical TLE for the spacecraft, and so the orbital sampling is not precisely the same as what the Aqua (or Aura) spacecraft actually flew. Additionally, we note that in contrast with Fig. 2a and b, there are no cloud or glint features in Fig. 2c. MERRAero is subsampled without regard to these issues as the model is capable of computing an AOT in all grid boxes regardless of cloud cover or other conditions that affect satellite viewing. The AOT from MERRAero is the all-sky AOT; that is, it is derived from the grid box mean aerosol and humidity fields.

The global, annual mean AOT time series from the MERRAero sub-samples are shown in Fig. 4 (black lines). MERRAero over-ocean AOT tends to be lower than the MODISderived sub-samples, and there is a trend toward decreasing AOT apparent in MERRAero that is not seen in the MODIS data. Furthermore, over most of the time series MERRAero has a higher over-ocean AOT than the DA-grade MODISderived AOT being assimilated. For now, we attribute these aspects of MERRAero to the fact that, despite having an assimilated, satellite-derived AOT product, MERRAero remains an aerosol transport model. So, for example, as data sets are not yet available to drive anthropogenic aerosol emissions in the model for the full time period being simulated, there is an imprint of model error present that the data assimilation evidently does not entirely correct. Over land the MERRAero global, annual mean AOT is more comparable in magnitude to the MODIS data, but the inter-annual variability is quite different. Again we emphasize that MERRAero is not subject to surface boundary conditions affecting the MODIS retrievals, and the over-land MERRAero averages include AOT values over bright desert and snow-covered surfaces. For both land and ocean the MERRAero global, annual mean AOT for all sub-samples are within 0.01 of the MERRAero full-swath averages.

The MERRAero $\triangle$ AOT spatial sampling artifact is shown in Figs. 9, 10, and S1 in the Supplement. It is generally the case that the MERRAero sampling artifact is smaller than what we derived from MODIS. This difference, however, is not always great. Seasonal peaks in the sampling artifact in South America, for example, can be as large in MERRAero as in MODIS, and are even somewhat larger in MERRAero for the African dust region. On the other hand, in China the seasonal peaks in sampling artifact are at most about half the magnitude of what was found in the MODIS analysis. In MERRAero, the sampling artifacts are small for the Asian outflow and Southern Africa regions, similar to what MODIS showed, whereas the Nile River region notably has a large excursion above the magnitude found in MODIS in AprilMay-June 2007. This excursion is traced to a May 2007 dust event in the Sahara that produces a high regional AOT for the curtain sampling and a low regional AOT for the full-swath sampling, highlighting the variability of small sources and the potential impact on seasonal-regional AOT statistics. A similar feature is seen in Southeast Asia for the JFM season in 2010, in this case attributable to a biomass burning feature preferentially sampled by the curtain sampling.

Finally, we exploit the fact that we are analyzing results of an aerosol transport model here. In the model run cycle, a radiative transfer code is called every time step, and top of atmosphere (TOA) and surface shortwave and long-wave radiative fluxes are computed. For each grid column the radiation call is made several times, both including and removing the effects of aerosols, and similarly the effects of clouds.

In Figs. 9, 10, and S1 in the Supplement, we also show the sampling artifact as computed in terms of the TOA all-sky shortwave flux with and without aerosols (this is the TOA shortwave aerosol direct radiative effect), where the magnitude of the sampling artifact $\Delta$ forcing is again the difference in the seasonal-regional mean between the samples having the highest and lowest mean values, analogous to Eq. (3). As we are sampling only during the daytime portion of the satellite orbit, we approximate the diurnally averaged radiative forcing sampling artifact by dividing the actual artifact computed from the instantaneous values by a factor of four. We note that the all-sky TOA aerosol radiative forcing is negative (cooling) over all regions considered except the Nile River region, where the forcing is positive owing to the exceedingly bright desert surface. The $\Delta$ forcing artifact is by construction defined positive.

In all regions except the Asian outflow region (where the AOT sampling artifact is small), the $\Delta$ forcing sampling 
artifact has seasonal peaks in excess of $1 \mathrm{~W} \mathrm{~m}^{-2}$, and it approaches $3 \mathrm{~W} \mathrm{~m}^{-2}$ in the Nile River region. There is not always a strong or obvious correlation between the MERRAero $\Delta$ forcing and $\Delta$ AOT sampling artifacts, reflecting the complexity of the forcing being a convolution of aerosol loading with the distributions of clouds and the varying, underlying surface properties. For example, the same $\Delta$ forcing sampling artifact can be computed under clear-sky conditions (i.e., removing the effects of clouds), in which case the forcing itself is more strongly correlated with the AOT in all regions.

\section{Discussion and conclusions}

We have used MODIS data and results of a global aerosol reanalysis to investigate the impact of spatial sampling on the statistics of AOT. From MODIS data, we showed significant differences in the global, annual mean AOT derived from along-track sampling (Fig. 4). The "sample-then-average" approach employed initially, however, could not disentangle the spatial sampling artifacts (which we are most interested in isolating) from the sensitivity of the MODIS AOT retrieval to viewing geometry.

Subsequently, we considered the observability problem: where the sub-sample could have obtained aerosol retrievals, where it could not, and where - compared to the fullswath values - differences in the regional and seasonal AOT are found. The observability-based "average-then-mask" approach (Sect. 2.4.2) mitigates biases associated with location in the MODIS swath, but greatly increases the sampling compared to an actual instrument having a narrower swath, because the full-swath MODIS instrument obtains much more frequent observations of any given location than an actual narrow-swath instrument would. This approach yielded global, annual mean AOT values that were insignificantly different from the full-swath AOT values, in contrast to the originally employed "sample-then-average" method; nevertheless, important regional differences remained. The $\Delta$ AOT spatial sampling artifact was typically small for our more ocean-influenced regions (e.g., African dust, Asian outflow), but could be as large as 0.1 in the seasonal AOT average for high-loading, near-source regions such as China and the Indo-Gangetic Plain. As a percentage of the full-swath seasonal-regional mean AOT, the sampling artifact was as large as $60 \%$ (South America), and was in many places around $20 \%$ (China, Indo-Gangetic Plain, Nile River). In almost all cases, the magnitude of the sampling artifact was largest for the curtain-like sampling, with smaller artifacts inferred when the narrow-swath sampling was compared to the full swath, as might be expected.

Further analysis of the MODIS data using the across-track sampling method suggested in Geogdzhayev et al. (2013) likewise yielded global, annual mean AOT values insignificantly different from the full-swath values, but again with significant regional differences, often exceeding the sampling artifact for our along-track sampling.

Finally, the MERRAero reanalysis results sampled along hypothetical orbital tracks also yielded global, annual mean AOT values insignificantly different from the full-swath sampling of the MERRAero AOT field. The MERRAero $\triangle$ AOT spatial sampling artifacts were generally similar in magnitude to the along-track MODIS sampling artifact. From the MERRAero results, we also computed a $\Delta$ forcing sampling artifact as the range in the seasonal-regional mean all-sky TOA aerosol forcing across all sampling strategies. In most regions this $\Delta$ forcing artifact had seasonal peaks larger than $1 \mathrm{~W} \mathrm{~m}^{-2}$, and in several regions it had seasonal mean peaks as large as $2-3 \mathrm{~W} \mathrm{~m}^{-2}$. The $\Delta$ forcing artifact is distinct from the $\Delta$ AOT artifact in that it bears an imprint of surface and cloud variability in addition to aerosol loading variability, and so reveals a different aspect of the spatial sampling issue explored here, i.e., the ability to constrain the climatically critical aerosol direct radiative forcing (Solomon et al., 2007).

Our analysis was focused on seasonal-regional spatial sampling artifacts, which capture aspects of the mean aerosol distributions. Folded into these mean field properties is variability occurring on much smaller spatiotemporal scales, including extreme events (i.e., volcanic eruptions, wildfires) that could be missed depending on the spatial sampling. The "average-then-mask" method employed for our MODIS along-track results would carry events to the sub-samples more completely than would be the case for the "samplethen-average" approach that more realistically represent the sampling of an actual instrument. Because of the aforementioned limitations of the "sample-then-average" data set, we do not fully assess here the sub-regional distribution of AOT and how that is impacted by spatial sampling, but this is an issue that needs further consideration.

We additionally investigated our ability to detect statistically significant trends in aerosol features as a function of spatial sampling. We find that the full-swath trends in our study are similar to the "contextually less-biased" assimilation-grade trends in Zhang and Reid (2010), suggesting that although contextual bias can be an issue, it probably does not diminish the applicability of our conclusions. Although the signs of the trends were similar for the various sampling strategies employed, magnitudes were in some places quite different. This is attributable in part to the MODIS view-angle bias, but also to differences in the spatial coverage. Again, most places on Earth are simply never observed with curtain-like sampling, including some major aerosol source regions. When the MODIS data set is gridded at the highest spatial resolution used here, the reduced spatial coverage has a profound impact on the ability to assign statistical significance to the trends (Fig. 12). For example, even the narrow N1 sampling could not assign significance at the $95 \%$ confidence level to any decadal-scale trends over Amazonia or the central United States, and had 
reduced confidence in western Africa and India. The patterns of significance were even less coherent for the curtainlike sampling. Analyzing the trends with the "average-thenmask" approach yields improvement in the ability to assign statistical significance in the narrower samples, but there are still broad regions where statistical significance cannot be assured without the full-swath sampling. Although the narrowswath sampling fares better than curtain sampling, without the context of a full swath imager's observations, there is little confidence in even these derived trends, a conclusion similar to one obtained by Zhang and Reid (2010). The conclusion is similar for the across-track sampling of the MODIS data, where - again - although the derived trend is similar in magnitude to the full-swath-derived trend, the ability to assign statistical significance is compromised by the poorer spatial sampling. On the other hand, aggregation of the subsampled AOT fields to coarser spatial resolution $\left(10^{\circ} \times 10^{\circ}\right.$, Figs. 14 and 15) drew out many common features in both the trend magnitude and statistical significance across sampling strategies, suggesting that narrow and even single-pixel wide sampling are sufficient for qualitative trend detection at these scales. Note that for sufficiently coarse spatial and temporal aggregation, all global sampling strategies should converge to the same values, regardless of sampling frequency. However, for finite time series, the ability to capture regional effects and to detect trends depends heavily on sampling frequency.

We note that the MODIS data set does not capture all aspects of the actual aerosol field, in part due to contextual limitations of the measurement technique, such as the lack of diurnal observations and the inability to retrieve AOT under and in the immediate vicinity of clouds (e.g., Zhang and Reid, 2009). Others have identified contextual issues with the MODIS data set over land (Hyer et al., 2011) and in coastal sites (Anderson et al., 2013). Other measurement approaches would enhance retrieval of aerosol properties over bright land surfaces and address these issues. Future aerosol instruments will undoubtedly improve upon MODIS data set in these and other respects, such as providing enhanced information about aerosol single scattering albedo and particle size, as well as other important drivers DARF (e.g., Loeb and Su, 2010). It was not our intention here to demonstrate the benefit of those enhanced capabilities, but rather to investigate the limits imposed on the measured AOT by one aspect of any future measurement strategy, its spatial coverage. That our results are broadly consistent between the analysis of MODIS data - however imperfect - and an aerosol transport model subject to its own biases, but biases which are different than MODIS's - increases confidence in the results.

Our main conclusions are thus that

- Spatial sampling is not a driver of uncertainty in the global, annual mean AOT, for the sampling strategies considered. This finding is robust for the "average-thenmask" along-track and across-track MODIS sampling, as well as for the MERRAero sampling, but not so for the "sample-then-average" approach, which aside from MODIS swath-related artifacts, is a better representation of the sampling from an actual instrument.

- Reduced spatial sampling introduces uncertainty into seasonal-regional mean AOT assessments. This was found for the along-track and across-track MODIS, sampling, and again as well for the MERRAero sampling. Seasonal peaks in the $\triangle$ AOT spatial sampling artifact were as large as 0.1 in high AOT regions, representing uncertainties as large as $60 \%$ of the full-swath AOT values in some places. This uncertainty was somewhat reduced, but not eliminated, when narrow-swath sampling was considered (i.e., when along-track curtain sampling was discarded).

- Reduced spatial sampling introduces uncertainty into seasonal-regional mean aerosol radiative forcing assessments. This analysis was performed in context of the MERRAero results, and we found that spatial sampling - convolving variability in aerosol loading, surface conditions, and cloud cover - introduced uncertainty of more than $1 \mathrm{~W} \mathrm{~m}^{-2}$ and as much as $2-3 \mathrm{~W} \mathrm{~m}^{-2}$ in most regions considered.

- Spatial sampling affects the derived magnitude and assignment of statistical significance in aerosol trends. Along-track curtain sampling results in reduced trend magnitude and essentially eliminates statistical confidence in the derived, decadal-scale trends when the data are aggregated at high spatial resolutions. Trend magnitudes and statistical significance were more similar to full-swath values for the narrow-swath sampling.

- Aerosol trends and statistical significance were found to be similar across sampling strategies when the trends were composed from coarsely gridded aggregates of the sub-sampled MODIS AOT data, suggesting that single pixel width sampling may be sufficient to detect and attribute trends at spatial scales on the order of $1000 \mathrm{~km}$. However, to determine radiative forcing, the surface albedo must also be taken into consideration, and on these large spatial scales, surface properties, particularly over land where AOD tends to be highest, vary over much shorter distances.

In summary, looking at both MODIS data and results of a global aerosol reanalysis, we conclude that spatial sampling matters. We further conclude that our analysis puts a lower bound on the uncertainty in the seasonal-regional AOT introduced by spatial sampling. Consideration of additional samplings (e.g., adding more along-track curtains) could act only in the direction of increasing the magnitude of our computed $\triangle$ AOT sampling artifact. There is also subsequent uncertainty attached to estimates of DARF due to spatial sampling, dependent not only on the variability in the aerosol load but 
also on surface reflectivity and clouds, and we were able to place a lower bound on this through our aerosol model analysis.

\section{The Supplement related to this article is available online at doi:10.5194/amt-7-2313-2014-supplement.}

Acknowledgements. This work was funded by the NASA Earth Science Division as part of the pre-formulation study for the Aerosol, Cloud, and ocean Ecosystem (ACE) Mission. We acknowledge Hal Maring, Paula Bontempi, Mark Schoeberl, David Starr, and Lisa Callahan for supporting this work. We thank Rich Ferrare, Alexei Lyapustin, Alexander Marshak, Jeffrey Reid, and Ellsworth Welton for comments on an early version of this manuscript. The MERRAero results derive from a number of people's work, including Arlindo da Silva, Ravi Govindaraju, and Anton Darmenov. The image of the Mona Lisa shown in Fig. 1 was taken from the website: https://en.wikipedia.org/wiki/File:Mona_ Lisa,_by_Leonardo_da_Vinci,_from_C2RMF_retouched.jpg.

Edited by: A. Lambert

\section{References}

Anderson, J. C., Wang, J., Zeng, J., Leptoukh, G., Petrenko, M., Ichoku, C., and $\mathrm{Hu}, \mathrm{C} .:$ Long-term statistical assessment of Aqua-MODIS aerosol optical depth over coastal regions: bias characteristics and uncertainty sources, Tellus B, 65, 20805, doi:10.3402/tellusb.v65i0.20805, 2013.

Anderson, T. L., Charlson, R., Winker, D., Ogren, J., and Holmen, K.: Mesoscale variations of tropospheric aerosols, J. Atmos. Sci., 60, 119-136, 2003.

Anderson, T. L., Charlson, R. J., Bellouin, N., Boucherm, O., Chin, M., Christopher, S. A., Haywood, J., Kaufman, Y. J., Kinne, S., Ogren, J. A., Remer, L. A., Takemura, T., Tanré, D., Torres, O., Trepte, C. R., Wielicki, B. A., Winker, D. M., and Yu, H.: An “ATrain" strategy for quantifying direct climate forcing by anthropogenic aerosols, B. Am. Meteorol. Soc., 86, 1795-1809, 2005.

Bréon, F.-M., Vermeulen, A., and Descloitres, J.: An evaluation of satellite aerosol products against sunphotometer measurements, Remote Sens. Environ., 115, 3102-3111, doi:10.1016/j.rse.2011.06.017, 2011.

Buchard, V., da Silva, A. M., Colarco, P., Krotkov, N., Dickerson, R. R., Stehr, J. W., Mount, G., Spinei, E., Arkinson, H. L., and He, H.: Evaluation of GEOS-5 sulfur dioxide simulations during the Frostburg, MD 2010 field campaign, Atmos. Chem. Phys., 14, 1929-1941, doi:10.5194/acp-14-1929-2014, 2014.

CCSP (US Climate Change Science Program): Synthesis and Assessment Product 2.3, in: Atmospheric aerosol properties and climate impacts, edited by: Chin, M., Kahn, R., and Schwartz, S., 116 pp., pub. National Aeronautics and Space Administration, Washington, D.C., USA, 2009.

Chin, M., Ginoux, P., Kinne, S., Torres, O., Holben, B., Duncan, B., Martin, R., Logan, J., Higurashi, A., and Nakajima, T.: Tropospheric aerosol optical thickness from the GOCART model and comparisons with satellite and Sun photometer measurements, J. Atmos. Sci., 59, 461-483, 2002.

Colarco, P., da Silva, A., Chin, M., and Diehl, T.: Online simulations of global aerosol distributions in the NASA GEOS-4 model and comparisons to satellite and ground-based aerosol optical depth, J. Geophys. Res.-Atmos., 115, D14207, doi:10.1029/2009JD012820, 2010.

Colarco, P. R., Remer, L. A., Kahn, R. A., Levy, R. C., and Welton, E. J.: Implications of satellite swath width on global aerosol optical thickness statistics, Atmos. Meas. Tech. Discuss., 5, 27952820, doi:10.5194/amtd-5-2795-2012, 2012.

Diner, D. J., Beckert, J., Reilly, T., Bruegge, C., Conel, J., Kahn, R., Martonchik, J. V., Ackerman, T. P., Davies, R., Gerstl, S. A. W., Gordon, H. R., Muller, J.-P., Myneni, R. B., Sellers, P. J., Pinty, B., and Verstraete, M.: Multi-angle Imaging SpectroRadiometer (MISR) - Instrument description and experiment overview, IEEE T. Geosci. Remote, 36, 1072-1087, 1998.

Diner, D. J., Ackerman, T. P., Anderson, T. L., Bösenberg, J., Braverman, A. J., Charlson, R. J., Collins, W. D., Davies, R., Holben, B. N., Hostetler, C. A., Kahn, R. A., Martonchik, J. V., Menzies, R. T., Miller, M. A., Ogren, J. A., Penner, J. E., Rasch, P. J., Schwartz, S. E., Seinfeld, J. H., Stephens, G. L., Torres, O., Travis, L. D., Wielicki, B. A., and Yu, B.: PARAGON: An Integrated Approach for Characterizing Aerosol Climate Impacts and Environmental Interactions, B. Am. Meteorol. Soc., 85, 1491-1501, doi:10.1175/BAMS-85-10-1491, 2004.

Geogdzhayev, I., Cairns, B., Alexandrov, M., and Mishchenko, M. I.: Statistical analysis of single-track instrument sampling in spaceborne aerosol remote sensing for climate research, J. Quant. Spectrosc. Ra., 121, 69-77, doi:10.1016/j.jqsrt.2013.02.003, 2013.

Hansen, J., Rossow, W., Carlson, B., Lacis, A., Travis, L., DelGenio, A., Fung, I., Cairns, B., Mishchenko, M., and Sato, M.: Lowcost long-term monitoring of global climate forgings and feedbacks, Climatic Change, 31, 247-271, 1995.

Holben, B., Eck, T., Slutsker, I., Tanre, D., Buis, J., Setzer, A., Vermote, E., Reagan, J., Kaufman, Y., Nakajima, T., Lavenu, F., Jankowiak, I., and Smirnov, A.: AERONET - A federated instrument network and data archive for aerosol characterization, Remote Sens. Environ., 66, 1-16, 1998.

Huneeus, N., Schulz, M., Balkanski, Y., Griesfeller, J., Prospero, J., Kinne, S., Bauer, S., Boucher, O., Chin, M., Dentener, F., Diehl, T., Easter, R., Fillmore, D., Ghan, S., Ginoux, P., Grini, A., Horowitz, L., Koch, D., Krol, M. C., Landing, W., Liu, X., Mahowald, N., Miller, R., Morcrette, J.-J., Myhre, G., Penner, J., Perlwitz, J., Stier, P., Takemura, T., and Zender, C. S.: Global dust model intercomparison in AeroCom phase I, Atmos. Chem. Phys., 11, 7781-7816, doi:10.5194/acp-11-7781-2011, 2011.

Hyer, E. J., Reid, J. S., and Zhang, J.: An over-land aerosol optical depth data set for data assimilation by filtering, correction, and aggregation of MODIS Collection 5 optical depth retrievals, Atmos. Meas. Tech., 4, 379-408, doi:10.5194/amt-4-379-2011, 2011.

Kahn, R. A.: Reducing the Uncertainties in Direct Aerosol Radiative Forcing, Surv. Geophys., 33, 701-721, doi:10.1007/s10712011-9153-z, 2012.

Kaufman, Y. J., Tanré, D., Remer, L. A., Vermote, E. F., Chu, A., and Holben, B. N.: Operational remote sensing of tropospheric 
aerosol over land from EOS moderate resolution imaging spectroradiometer, J. Geophys. Res., 102, 17051-17067, 1997.

Kessner, A. L., Wang, J., Levy, R. C., and Colarco, P. R.: Remote sensing of surface visibility from space: A look at the United States East Coast, Atmos. Environ., 81, 136-147, doi:10.1016/j.atmosenv.2013.08.050, 2013.

Kiehl, J. T.: Twentieth century climate model response and climate sensitivity, Geophys. Res. Lett., 34, L22710, doi:10.1029/2007GL031383, 2007.

Kinne, S., Schulz, M., Textor, C., Guibert, S., Balkanski, Y., Bauer, S. E., Berntsen, T., Berglen, T. F., Boucher, O., Chin, M., Collins, W., Dentener, F., Diehl, T., Easter, R., Feichter, J., Fillmore, D., Ghan, S., Ginoux, P., Gong, S., Grini, A., Hendricks, J., Herzog, M., Horowitz, L., Isaksen, I., Iversen, T., Kirkevåg, A., Kloster, S., Koch, D., Kristjansson, J. E., Krol, M., Lauer, A., Lamarque, J. F., Lesins, G., Liu, X., Lohmann, U., Montanaro, V., Myhre, G., Penner, J., Pitari, G., Reddy, S., Seland, O., Stier, P., Takemura, T., and Tie, X.: An AeroCom initial assessment - optical properties in aerosol component modules of global models, Atmos. Chem. Phys., 6, 1815-1834, doi:10.5194/acp-6-1815-2006, 2006.

Levy, R. C., Remer, L. A., and Dubovik, O.: Global aerosol optical properties and application to Moderate Resolution Imaging Spectroradiometer aerosol retrieval over land, J. Geophys. Res., 112, D13210, doi:10.1029/2006JD007815, 2007a.

Levy, R. C., Remer, L. A., Mattoo, S., Vermote, E. F., and Kaufman, Y. J.: Second-generation operational algorithm: Retrieval of aerosol properties over land from inversion of Moderate Resolution Imaging Spectroradiometer spectral reflectance, J. Geophys. Res., 112, D13211, doi:10.1029/2006JD007811, 2007 b.

Levy, R. C., Remer, L. A., Kleidman, R. G., Mattoo, S., Ichoku, C., Kahn, R., and Eck, T. F.: Global evaluation of the Collection 5 MODIS dark-target aerosol products over land, Atmos. Chem. Phys., 10, 10399-10420, doi:10.5194/acp-10-10399-2010, 2010.

Levy, R. C., Mattoo, S., Munchak, L. A., Remer, L. A., Sayer, A. M., Patadia, F., and Hsu, N. C.: The Collection 6 MODIS aerosol products over land and ocean, Atmos. Meas. Tech., 6, 29893034, doi:10.5194/amt-6-2989-2013, 2013.

Loeb, N. G. and Su, W.: Direct Aerosol Radiative Forcing Uncertainty Based on a Radiative Perturbation Analysis, J. Climate, 23, 5288-5293, doi:10.1175/2010JCLI3543.1, 2010.

McComiskey, A., Schwartz, S. E., Schmid, B., Guan, H., Lewis, E. R., Ricchiazzi, P., and Ogren, J. A.: Direct aerosol forcing: Calculation from observables and sensitivities to inputs, J. Geophys. Res., 113, D09202, doi:10.1029/2007JD009170, 2008.

Myhre, G., Samset, B. H., Schulz, M., Balkanski, Y., Bauer, S., Berntsen, T. K., Bian, H., Bellouin, N., Chin, M., Diehl, T., Easter, R. C., Feichter, J., Ghan, S. J., Hauglustaine, D., Iversen, T., Kinne, S., Kirkevåg, A., Lamarque, J.-F., Lin, G., Liu, X., Lund, M. T., Luo, G., Ma, X., van Noije, T., Penner, J. E., Rasch, P. J., Ruiz, A., Seland, Ø., Skeie, R. B., Stier, P., Takemura, T., Tsigaridis, K., Wang, P., Wang, Z., Xu, L., Yu, H., Yu, F., Yoon, J.-H., Zhang, K., Zhang, H., and Zhou, C.: Radiative forcing of the direct aerosol effect from AeroCom Phase II simulations, Atmos. Chem. Phys., 13, 1853-1877, doi:10.5194/acp-13-18532013, 2013.

NRC: Earth Science and Applications from Space: National Imperatives for the Next Decade and Beyond, National Academies
Press, available at: http://www.nap.edu/catalog/11820.html (last access: 29 July 2014), 2007.

Randles, C. A., Kinne, S., Myhre, G., Schulz, M., Stier, P., Fischer, J., Doppler, L., Highwood, E., Ryder, C., Harris, B., Huttunen, J., Ma, Y., Pinker, R. T., Mayer, B., Neubauer, D., Hitzenberger, R., Oreopoulos, L., Lee, D., Pitari, G., Di Genova, G., Quaas, J., Rose, F. G., Kato, S., Rumbold, S. T., Vardavas, I., Hatzianastassiou, N., Matsoukas, C., Yu, H., Zhang, F., Zhang, H., and Lu, P.: Intercomparison of shortwave radiative transfer schemes in global aerosol modeling: results from the AeroCom Radiative Transfer Experiment, Atmos. Chem. Phys., 13, 2347-2379, doi:10.5194/acp-13-2347-2013, 2013.

Remer, L. A., Kaufman, Y., Tanre, D., Mattoo, S., Chu, D., Martins, J. V., Li, R.-R., Ichoku, C., Levy, R. C., Kleidman, R. G., Eck, T. F., Vermote, E., and Holben, B. N.: The MODIS aerosol algorithm, products, and validation, J. Atmos. Sci., 62, 947-973, 2005.

Remer, L. A., Kleidman, R. G., Levy, R. C., Kaufman, Y. J., Tanré, D., Mattoo, S., Martins, J. V., Ichoku, C., Koren, I., Yu, H., and Holben, B. N.: Global aerosol climatology from the MODIS satellite sensors, J. Geophys. Res., 113, D14S07, doi:10.1029/2007JD009661, 2008.

Rienecker, M. M., Suarez, M., Todling, R., Bacmeister, J., Takacs, L., Liu, H. C., Gu, W., Sienkieicz, M., Koster, R., Gelaro, R., Stajner, I., and Nielsen, J.: The GEOS-5 Data Assimilation SystemDocumentation of Version 5.0.1, 5.1.0, and 5.2.0, NASA Technical Report Series on Global Modeling and Data Assimilation, edited by: Suarez, M. J., 27, 1-118, 2008.

Rienecker, M. M., Suarez, M. J., Gelaro, R., Todling, R., Bacmeister, J., Liu, E., Bosilovich, M. G., Schubert, S. D., Takacs, L., Kim, G.-K., Bloom, S., Chen, J., Collins, D., Conaty, A., Da Silva, A., Gu, W., Joiner, J., Koster, R. D., Lucchesi, R., Molod, A., Owens, T., Pawson, S., Pegion, P., Redder, C. R., Reichle, R., Robertson, F. R., Ruddick, A. G., Sienkiewicz, M., and Woollen, J.: MERRA: NASA's Modern-Era Retrospective Analysis for Research and Applications, J. Climate, 24, 3624-3648, doi:10.1175/JCLI-D-11-00015.1, 2011.

Schulz, M., Textor, C., Kinne, S., Balkanski, Y., Bauer, S., Berntsen, T., Berglen, T., Boucher, O., Dentener, F., Guibert, S., Isaksen, I. S. A., Iversen, T., Koch, D., Kirkevåg, A., Liu, X., Montanaro, V., Myhre, G., Penner, J. E., Pitari, G., Reddy, S., Seland, $\varnothing .$, Stier, P., and Takemura, T.: Radiative forcing by aerosols as derived from the AeroCom present-day and pre-industrial simulations, Atmos. Chem. Phys., 6, 5225-5246, doi:10.5194/acp-65225-2006, 2006.

Seinfeld, J., Kahn, R., Anderson, T., Charlson, R., Davies, R., Diner, D., Ogren, J., Schwartz, S., and Wielicki, B.: Scientific objectives, measurement needs, and challenges motivating the PARAGON aerosol initiative, B. Am. Meteorol. Soc., 85, 15031509, doi:10.1175/BAMS-85-10-1503, 2004.

Sessions, W. R., Reid, J. S., Benedetti, A., Colarco, P. R., da Silva, A., Lu, S., Sekiyama, T., Tanaka, T. Y., Baldasano, J. M., Basart, S., Brooks, M. E., Eck, T. F., Iredell, M., Hansen, J. A., Jorba, O. C., Juang, H.-M. H., Lynch, P., Morcrette, J.-J., Moorthi, S., Mulcahy, J., Pradhan, Y., Razinger, M., Sampson, C. B., Wang, J., and Westphal, D. L.: Development towards a global operational aerosol consensus: basic climatological characteristics of the International Cooperative for Aerosol Prediction Multi- 
Model Ensemble (ICAP-MME), Atmos. Chem. Phys. Discuss., 14, 14933-14998, doi:10.5194/acpd-14-14933-2014, 2014.

Solomon, S., Qin, D., Manning, M., Marquis, M., Averyt, K., Tignor, M. M. B., Miller Jr., H. L., and Chen, Z.: Climate Change 2007: The Physical Sciences Basis. Cambridge University Press, Cambridge, UK, 996 pp., 2007.

Starr, D., Callahan, L., Remer, L., et al.: Aerosol, Cloud and Ecosystem (ACE) Proposed Satellite Mission: Study Report, available at: http://dsm.gsfc.nasa.gov/ace/documents/ Draft_ACE_Report2010.pdf (last access: 29 July 2014), 2010.

Stier, P., Schutgens, N. A. J., Bellouin, N., Bian, H., Boucher, O., Chin, M., Ghan, S., Huneeus, N., Kinne, S., Lin, G., Ma, X., Myhre, G., Penner, J. E., Randles, C. A., Samset, B., Schulz, M., Takemura, T., Yu, F., Yu, H., and Zhou, C.: Host model uncertainties in aerosol radiative forcing estimates: results from the AeroCom Prescribed intercomparison study, Atmos. Chem. Phys., 13, 3245-3270, doi:10.5194/acp-13-3245-2013, 2013.

Tanré, D., Herman, M., and Kaufman, Y.: Information on aerosol size distribution contained in solar reflected spectral radiances, J. Geophys. Res., 101, 19043-19060, 1996.

Tanré, D., Kaufman, Y., Herman, M., and Mattoo, S.: Remote sensing of aerosol properties over oceans using the MODIS/EOS spectral radiances, J. Geophys. Res., 102, 16971-16988, 1997.

Textor, C., Schulz, M., Guibert, S., Kinne, S., Balkanski, Y., Bauer, S., Berntsen, T., Berglen, T., Boucher, O., Chin, M., Dentener, F., Diehl, T., Easter, R., Feichter, H., Fillmore, D., Ghan, S., Ginoux, P., Gong, S., Grini, A., Hendricks, J., Horowitz, L., Huang, P., Isaksen, I., Iversen, I., Kloster, S., Koch, D., Kirkevåg, A., Kristjansson, J. E., Krol, M., Lauer, A., Lamarque, J. F., Liu, X., Montanaro, V., Myhre, G., Penner, J., Pitari, G., Reddy, S., Seland, $\varnothing .$, Stier, P., Takemura, T., and Tie, X.: Analysis and quantification of the diversities of aerosol life cycles within AeroCom, Atmos. Chem. Phys., 6, 1777-1813, doi:10.5194/acp-6-1777-2006, 2006.
Weatherhead, E. C., Reinsel, G. C., Tiao, G. C., Meng, X. L., Choi, D., Cheang, W. K., Keller, T., DeLuisi, J., Wuebbles, D. J., and Kerr, J. B.: Factors affecting the detection of trends: Statistical considerations and applications to environmental data, J. Geophys. Res.-Atmos., 103, 17149-17161, 1998.

Winker, D. M., Pelon, J., Coakley, J. A. J., Ackerman, S. A., Charlson, R. J., Colarco, P. R., Flamant, P., Fu, Q., Hoff, R. M., Kittaka, C., Kubar, T. L., Le Treut, H., McCormick, M. P., Megie, G., Poole, L., Powell, K., Trepte, C., Vaughan, M. A., and Wielicki, B. A.: The CALIPSO Mission: A Global 3D View of Aerosols and Clouds, B. Am. Meteorol. Soc., 91, 1211-1229, doi:10.1175/2010BAMS3009.1, 2010.

Witte, J. C., Douglass, A. R., da Silva, A., Torres, O., Levy, R., and Duncan, B. N.: NASA A-Train and Terra observations of the 2010 Russian wildfires, Atmos. Chem. Phys., 11, 9287-9301, doi:10.5194/acp-11-9287-2011, 2011.

Xiong, X., Che, N., and Barnes, W. L.: Terra MODIS On-Orbit Spectral Characterization and Performance, IEEE T. Geosci. Remote, 44, 2198-2206, 2006.

Zhang, J. and Reid, J. S.: MODIS aerosol product analysis for data assimilation: Assessment of over-ocean level 2 aerosol optical thickness retrievals, J. Geophys. Res., 111, D22207, doi:10.1029/2005JD006898, 2006.

Zhang, J. and Reid, J. S.: An analysis of clear sky and contextual biases using an operational over ocean MODIS aerosol product, Geophys. Res. Lett., 36, L15824, doi:10.1029/2009GL038723, 2009.

Zhang, J. and Reid, J. S.: A decadal regional and global trend analysis of the aerosol optical depth using a data-assimilation grade over-water MODIS and Level 2 MISR aerosol products, Atmos. Chem. Phys., 10, 10949-10963, doi:10.5194/acp-1010949-2010, 2010. 